\title{
Do prior interactions breed cooperation in construction projects? The mediating role of contracts
}

DOI:

10.1016/j.jproman.2017.02.019

\section{Document Version}

Accepted author manuscript

Link to publication record in Manchester Research Explorer

\section{Citation for published version (APA):}

Wang, Y., Chen, Y., Fu, Y., \& Zhang, W. (2017). Do prior interactions breed cooperation in construction projects? The mediating role of contracts. International Journal of Project Management, 35(4), 633-646.

https://doi.org/10.1016/j.ijproman.2017.02.019

\section{Published in:}

International Journal of Project Management

\section{Citing this paper}

Please note that where the full-text provided on Manchester Research Explorer is the Author Accepted Manuscript or Proof version this may differ from the final Published version. If citing, it is advised that you check and use the publisher's definitive version.

\section{General rights}

Copyright and moral rights for the publications made accessible in the Research Explorer are retained by the authors and/or other copyright owners and it is a condition of accessing publications that users recognise and abide by the legal requirements associated with these rights.

\section{Takedown policy}

If you believe that this document breaches copyright please refer to the University of Manchester's Takedown Procedures [http://man.ac.uk/04Y6Bo] or contact uml.scholarlycommunications@manchester.ac.uk providing relevant details, so we can investigate your claim.

\section{OPEN ACCESS}




\title{
Do Prior Interactions Breed Cooperation in Construction
}

\section{Projects? The Mediating Role of Contracts}

\author{
Yu Wang ${ }^{\mathrm{a}}$, Yongqiang Chen ${ }^{\mathrm{b}}$, Yongcheng $\mathrm{Fu}^{\mathrm{c}}$, Wenjing Zhang ${ }^{\mathrm{d}}$ \\ ${ }^{a}$ College of Management and Economics, Tianjin University, Tianjin 300072, P.R. China. Email: \\ wangyu4869@126.com \\ ${ }^{b}$ College of Management and Economics, Tianjin University, Tianjin 300072, P.R. China. Email: \\ symbolpmc@vip.sina.com \\ ${ }^{c}$ Alliance Manchester Business School, The University of Manchester, Manchester, M15 6PB, UK. Email: \\ yongcheng.fu@postgrad.mbs.ac.uk \\ ${ }^{d}$ College of Management and Economics, Tianjin University, Tianjin 300072, P.R. China. Email: \\ zhangwenjing91@126.com
}

\section{Corresponding author:}

Yongcheng Fu 
3 Abstract:

\section{Do Prior Interactions Breed Cooperation in Construction Projects? The Mediating Role of Contracts}

There has long been inconsistence on the relationship among prior interactions, contracts and cooperative behavior. This study aims to examine how prior interactions affect cooperative behavior, including the effects of prior interactions on cooperative behavior and the mediating role of the contract between prior interactions and cooperative behavior. We classify cooperative behavior as in-role and extra-role behavior, and contract as a three-dimensional construct, including control, coordination and adaptation. Collecting data from 200 contractors in Chinese construction industry, the empirical results demonstrate the significance of the effect of prior interactions, the relationship between contract and cooperative behavior, and the mediating role of contractual coordination. According to our result, increasing contractual coordination emerge from prior interactions, while contractual control and adaptation is not related to these repeated collaborations. The findings reflect the interconnectedness of real-life projectsand provide a nuanced explanation to the complex relationships among prior interactions, contracts and cooperative behavior.

Keywords: construction project, inter-organizational relationship, prior interactions, contract, cooperative behavior.

\section{Introduction}

In construction industry, repeated transactions often take place between the same pair of owner and contractor. The emergent process resulting from prior ties is likely to alter subsequent governance design as well as partners' behavior (Poppo et al. 2008; Gulati 1995). Many believed that repeated exchanges generate trust and learning which make partners better able to deal with each other (Mayer and Argyres 2004; Ryall and Sampson 2009).

Thereby, we consider prior interactions may facilitate cooperative behavior. During the 
continuing interacting process there emerge alternative means to cope with cooperation risks. As mechanisms for achieving cooperation in inter-organizational transactions, contracts have been long regarded as formal governance to limit potential opportunism (Williamson 1985).

However, inconsistent evidence exists for the relationship among prior interactions, contracts and cooperative behavior. First, with respect to contracts and cooperative behavior, previous literature provides plenty of evidence on the positive relationship between the two. Some argue that contracts aims to clarifying partners' role and responsibilities (Luo, 2002a), developing trust and encouraging commitments (Poppo and Zenger 2002; Lui and Ngo 2004) such that idiosyncratic and deviant behavior will be alleviated and parties will perform in accordance with the mutual expectations (Salbu 1997). Consequently, cooperation is enhanced. In contrast, some scholars hold the opposite view that the use of contractual control signals distrust which is detrimental to cooperative relationship and even gives rise to opportunistic behavior that cannot be specified by contracts (Ghoshal and Moran 1996; Bernheim and Whinston 1998).

Second, there is also a growing debate on how contract design changes with repeated relationships (Ryall and Sampson 2009). Quite a few of studies indicates that contract may change with prior collaborative histories. Poppo and Zenger (2002) revealed that norms and social ties emerging from prior exchange would complement contractual governance. Ryall and Sampson (2003) focus on the effect of prior alliances on contract structure and find that contracts are more complete or detailed if firms have prior alliances with the same firm or other firms. Their subsequent study draws a further conclusion that a firm's contracts tend to be more detailed and more likely to include penalties when it engages in frequent deals, especially when the prior deals are between the same partners (Ryall and Sampson 2009). On the contrary, evidence from Reuer and Arino (2007) shows that more prior alliances between the partners would lead to less contractual complexity. The major point of contention lies in that whether contract can be substituted by trust and inter-organizational routines fostered in prior relationships or it will be more detailed due to learning effects which lower ex ante 
contracting costs (Mayer and Argyres 2004).

54 In our views, the conflicts among previous findings may be a consequence of insufficiency in dimension dividing of contract and cooperative behavior. Different contract provisions are

56 designed for different purposes. However, the global indicators of contractual complexity rather than particular provisions are often adopted as measurement of contract (Poppo and Zenger 2002). Similarly, cooperative behavior can also be viewed as a two-dimension construct, including in-role behavior and extra-role behavior (Katz 1964). Extra-role behavior is mostly discussed as organizational citizenship behavior at the individual level but is rarely mentioned at the transaction level, in spite of the fact that the firms can make extra efforts to enhance project performance besides completing the tasks specified in the contract. Thus, the global measurement can't distinguish the effects of certain factors on particular contractual provisions (Reuer and Arino 2007) as well as the effects of particular contractual provisions on certain type of cooperative behavior, which might result in confusion. We suggest that a better alternative is to investigate contract from a multi-functional perspective, namely

67 contractual control, coordination and adaption.

Based on observations and theories, we propose that prior interactions are likely to affect partners' cooperative behavior and contracts in construction projects. Moreover, from the

70 Transaction Cost Economics perspective (Williamson 1979), the contract fosters partners' cooperative behavior through reducing their opportunistic behavior. Relying on the effect, contracts may mediate prior interactions and contractors' cooperative behavior. Hence, this study develops a model to address the following research questions:

How do prior interactions affect cooperative behavior:

And 3) what effects do prior interactions have on the subsequent contract and does the contract mediate the effect of prior interactions on cooperative behavior?

The main contributions this study intended to offer are to explicate the nature of the linkage 
between the three functions of contract and the two types of cooperative behavior, and demonstrate the different paths through which prior interactions affect contract and cooperative behavior. Elaborating these more fine-grained effects can brings new explanation for previous controversy and offer some insight into the determinants of cooperative behavior. The remainder of this study is organized as follows. First, we review previous relevant literature and develop hypotheses. Second, we present the description of methodology and statistical results. And then, we have discussions on the results. Finally, we make conclusions and give managerial implications.

\section{Theoretical Foundation and Hypotheses}

\subsection{Cooperative Behavior}

Cooperation is a necessary ingredient for the success of construction projects. However, partners' cooperative behavior is not automatic or easily fostered (Malhotra and Lumineau 2011). Many efforts have been made to identify determinants of cooperation, but most of them consider cooperation as a general concept (Das and Teng 1998; Luo 2002a, 2002b), or measure it as performance (Luo 2008). Few studies distinguish different types of cooperative behavior. The seminal work of Katz (1964) proposes a two-dimensional construct of cooperative behavior, including in-role behavior and extra-role behavior. The in-role behavior refers to following mandatory rules or role descriptions. Obviously, the in-role behavior is the minimal level of standards for work. But if only relying on the minimal level behavior, organizations are difficult to operate effectively. Hence, it requires another type of behavior that is referred to as extra-role behavior. The extra-role behavior is the voluntary and spontaneous behavior, usually beyond the specified role descriptions. For example, the contractor may propose constructive suggestions for the project design document, or improve project value by a more appropriate project schedule.

The concepts of in-role and extra-role behavior derived from organization behavior field (Ziegler and Schlett 2016; Anvuur and Kumaraswamy 2012). Since the behavior of an 
organization is substantially done by its members, this classification can be reasonably extended to organizational level (Fu et al. 2015; Wuyts 2007). The applicability of the concept borrowing has been verified in the field of inter-organizational relationships

109 including construction projects, such as behavior of suppliers and buyers in the supply chain

110 (Kashyap and Sivadas 2012), or behavior of owners and contractors in construction projects

111 (Gil 2009). Due to the complexity of construction projects, only depending on the blueprints

112 of prescribed behavior would make projects very fragile and likely to breakdown. Actually,

113 partners' behavior usually tends to be composed of prescribed behavior and spontaneous

114 behavior. Thus, the concepts of in-role and extra-role behavior could better capture the reality

115 of behavior in construction projects.

\section{$116 \quad 2.2$ Contract}

117 Referring to inter-organizational cooperation, the contract is widely accepted as one

118 fundamental element to maintain inter-organizational relationship and reduce transaction

119 hazard. Scholars have presented two types of risks in inter-organizational relationships:

120 relational risk and performance risk (Das and Teng, 1996). According to Mellewigt et al.

121 (2012), relational risk relates to the hazards of partners' self-interested behavior. Such

122 non-cooperative behavior leads to the probability and consequences of unsatisfactory cooperation. However, there may exist performance risk (i.e. the hazards of unable to achieve

124 the performance objectives) even with full cooperation between transacting parties. On

125 account of different concerns of inter-organizational relationship risks, a three-function model

126 in contract studies is proposed, namely control, coordination and adaption (Mellewigt et al.

127 2012).

128 Relational risk is caused by potential opportunism and manifests in non-cooperative 129 behavior. Contracts provide an institutional framework for cooperation, within which partners 130 perform their rights and obligations (Gulati 1995). From Transaction Cost Economics 131 perspective, organizations use various contractual arrangements to safeguard investments 132 against misappropriation and reduce exchange hazards. Thus, contractual control provisions 
are designed to avoid relational risk. Control is the first function of the contract that has been recognized. In earlier and even contemporary literature, contracts are generally regarded as a uni-dimensional construct, which aim at controlling partner's opportunistic behavior.

Performance risk has two major sources. The first one is related to task interdependence and project complexity, which are prominent in construction projects. Contractual coordination clauses are designed to deal with this issue. Following previous research on analyses of contractual provisions (Parkhe 1993; Reuer and Arino 2007; Ryall and Sampson 2009), it is found that contracts serve for another purpose, that is, coordinating participants' behavior. Contractual coordination, through specifying task description (Argyres et al. 2007), interaction interfaces (Susarla et al. 2010), reporting procedures (Reuer and Arino 2007) and project milestones (Chang and Shen 2009), guides contractors to align actions with owners and achieve collective goals. Coordination provisions are particularly necessary when there are task interdependence and heterogeneous participants (Mellewigt et al. 2012). The former two dimensions of contracts focus on aligning partner's intentions or behavior, but construction projects are faced with risks not only from human variability but also environmental disturbances (Luo 2002a). Such unanticipated contingencies in the transaction environment are the second source of performance risk. Derived from future uncertainty and human bounded rationality (Williamson 1979), contracts also function as contingency adaptability to cope with unforeseen events in the future. Adaptation provisions aim at specifying principles or guidelines on how to handle unanticipated events that may arise during collaboration process (Schepker et al. 2014; Mellewigt et al. 2012). Especially in long-term projects, the increased possibility of encountering changes needs more governance flexibility to adapt to the future environment, avoiding breakdowns resulting from environmental disturbances.

Overall, for purpose of mitigating different risks in inter-organizational relationships, contracts serve as a three-functional instrument by limiting partners' opportunism, aligning each other's actions, and coping with future environmental uncertainty. The construct of 

consider three distinct contractual functions simultaneously (Lui and Ngo 2004; Salbu 1997;

162 Zhang et al. 2016). Hence, this study would take a holistic view to distinguish the effects of

163 three distinct contractual functions.

\subsection{Prior Interactions}

It is generally thought that economic transactions are discrete and one-off, especially the long-term construction projects, and the interconnectedness of transactions is often neglected (Batenburg et al. 2003), which means that transactions are regarded as independent and successive collaborative relationships between firms are ignored. Actually, sociologists have noticed the importance of prior interactions in economic transactions and emphasized that prior interactions would shape subsequent transactions governance or partners' behavior (Gulati 1995; Heide and John 1992). Some research has also implied the effects of prior interactions. Gulati and Singh (1998) contended that firms with prior ties are less likely to choose more hierarchical structure for their subsequent alliances. The trust developed over these prior ties may alleviate concerns of opportunism. Lumineau and Henderson (2012) found that partners who have cooperated before would rather adopt a cooperative negotiation strategy than a competitive strategy. Mellewigt et al. (2012) based on large amount of literature review advanced some propositions concerning the effects of prior interactions on contractual design and performance outcomes.

179 These evidences reinforce the importance of prior interactions. Cooperation experience is 180 likely to exert influences on subsequent transactions. However, due to the low transaction 181 frequency of construction industry, project interconnectedness doesn't receive sufficient attention. In extant literature, the effects of prior interactions in construction projects are sparsely noted. Therefore, this study would fill the gap to examine the effects of prior interactions in construction projects.

\subsection{Prior Interactions and Cooperative Behavior}

While many economics researchers often overlook prior interactions in economic 
transactions, sociologists address the existence of prior interactions and argue that economic exchange is embedded in social structure (Heide and John 1992). Gulati (1995) uses prior alliances as the proxy of trust. It indicates that the prior interactions foster inter-partner trust. The prior interactions often become overlaid with social content that carries strong expectations of trust and confidence in each other's intentions or behavior (Lui and Ngo 2004; Granovetter 1985). The increased interactions provide partners with opportunities to learn idiosyncrasies of each other, leading to high transaction efficiency. There may be inter-organizational routines developing through successive collaborations (Arino and Reuer 2004). These routines would motivate partners to conform to the each other's expectations and guide them to make commitments (Macaulay 1963).

Moreover, the long cooperation history also signals a positive reputation of partners. Out of the intention to preserve their good reputation, partners tend to make more commitments (Ryall and Sampson 2009). A longer transaction history could enhance the level and range of cooperation over time (Kim et al. 2010). Partners with long cooperation history would like to go extra miles to assure each other's satisfaction (Das and Teng 1998). Thus, we develop the following hypothesis:

Hypothesis 1: Prior interactions are positively associated with (a) in-role behavior and (b) extra-role behavior.

\subsection{Contract and Cooperative behavior}

When organizations enter one exchange, the biggest concern of them is the predictability of counterparty's behavior (Gulati 1995). The explicitly-stipulated contracts are devised to make partner's behavior predictable (Kazt 1964).

According to the behavioral assumption of Transaction Cost Economics, human have potential opportunism and tend to seek self-interest with guiles (Williamson 1985). The contract is an important mechanism by which one organization protects themselves from counterparty's opportunism (Cao and Lumineau 2015). With the aid of contractual provisions concerning controlling, it achieves to reduce opportunistic behavior and safeguard 
investments against misappropriation by the partner (Schepker et al. 2014).

215 Contract also set legal punishments and economic penalties for incompliance. Since the

216 threat of these severe punishments or penalties, partners would be encouraged to comply with

217 contractual agreement and other mandatory rules (Mellewigt et al. 2012; Lumineau and

218 Malhotra 2011). The greater complexity of contractual control is (i.e. the more inclusive and

219 specific contractual control provisions are), the more likely partners will fulfill their

220 prescribed tasks. Thus, we develop the following hypothesis:

221 Hypothesis 2a: Contractual control is positively associated with in-role behavior.

222 Contractual control limits partners' opportunistic behavior and facilitates in-role behavior.

223 However, as to the work beyond contractual requirements, contractual control may have a contrary effect on it.

225 Previous research has argued that contractual control may damage trust and ruin the cooperative relationships (Cao and Lumineau 2015), while another stream of studies holds the opposite view that based on the clearly-articulated contractual control makes partners build trust and then encourages more commitments (Poppo and Zenger 2002; Lui and Ngo 2004). One explanation to this contradictory may lie in effects of contractual control on different types of cooperative behavior. The effect of control provisions on in-role behavior has been deducted above - in fear of legal punishments and economic penalties, partners would perform what contracts stipulate. However, whether to fulfill extra-role behavior more depends on relationship between partners or willingness of partners, but is hardly manipulated by contractual control provisions. The increased number and stringency of contractual control provisions signals a lack of trust, which is detrimental to relationship quality between partners. In this case, partners are less likely to take innovative and spontaneous activities beyond their work scope. Thus, we develop the following hypothesis:

238 Hypothesis 2b: Contractual control is negatively associated with extra-role behavior.

239 Contractual control focuses on negative aspects of human variability, while contractual coordination focuses on the positive aspect of how to align partners' action and achieve 
collective goals (Lumineau and Malhotra 2011). Coordination clauses describe tasks interfaces (Argyres and Mayer 2007), reporting procedures and regular meetings (Reuer and Arino 2007), and project schedule and milestones (Schepker et al. 2014; Chang and Shen 2009).

Contractual coordination is particularly necessary when a transaction is characterized by a high degree of task interdependence and heterogeneous participants (Mellewigt et al. 2012).

247 Coordination-oriented provisions are intended to mitigate the risks of misunderstanding and missteps that might disrupt cooperative behavior. Lumineau and Malhotra (2011)'s study suggested that the greater contractual coordination would improve information exchange and cooperation. Through guiding partners to "what we want to achieve and how" (Woolthuis et al. 2005), contractual coordination ensures partners' shared understanding of the relationship (Lumineau and Malhotra 2011) and facilitates goal congruence between partners (Chang and Shen 2009).

Furthermore, coordination provisions support various forms of communication, such as reporting, regular meeting and so on. These appropriate linkages between partners breed high trust (Malhotra and Lumineau 2011). Once trust has been established between partners, partners tend to take an active part in work, and even undertake voluntarily the extra tasks. Thus, we develop the following hypothesis:

Hypothesis 3: Contractual coordination is positively associated with (a) in-role behavior and (b) extra-role behavior.

While the former two dimensions of contracts are intended to respond to human variability, contracts also serve the third function to cope with environmental uncertainty. Because of future uncertainty and human bounded rationality, it is impossible to write a complete contract which can foresee all possible events in the future (Williamson 1979). To avoid being vulnerable to environmental risks, contractual adaptation specifies principles or guidelines on how to handle unanticipated events during the collaboration process ( Schepker et al. 2014; Mellewigt et al. 2012). 

proceed, which ensures partners to feel relieved to make commitment. Generally speaking,

270 there would include more adaptation provisions in the long-term contract, because the

271 long-term transactions are likely to be disturbed by more changes (Hviid 2000). Preparing alternatives or respond principles in advance would reduce the possibility of severe loss or breakdowns of transactions (Luo 2002b).

274 The well-designed adaptation provisions indicate partners' intentions on continuing and completing transactions (Das and Teng 1998), which would motivate each other to undertake more works voluntarily.

Hypothesis 4: Contractual adaptation is positively associated with (a) in-role behavior and (b) extra-role behavior.

\section{$279 \quad 2.6$ Prior Interactions and Contract}

280 Contractual design is influenced by the extent that the partners have known each other (Luo 281 2002a). Previous research has debated over the effects of prior interactions on subsequent contract. For example, Reuer and Arino (2007) show that prior ties would lead to less contractual complexity; whereas Poppo and Zenger (2002) reveal that norms and social ties emerging from prior exchange would complement contractual governance. The conflicting findings may be a consequence of different measurement in previous research. For example, Reuer and Arino (2007) measure prior ties as a dummy variable just indicate the presence or absence of prior alliances. Poppo and Zenger (2002) regarded contract as a uni-dimensional construct and used one global item to measure it. This study measures prior interactions by the frequency of previous cooperation (see 3.2 Measures below), as well as distinguishes between contractual control, coordination and adaptation. In awareness of these distinct contractual functions, the effects of prior interactions on contracts should be reinterpreted. contract. Some scholars claimed that the development of trust or inter-organizational routines from past relationships would substitute control provisions, thus leading to less contractual 
control (Reuer and Arino 2007). However, Das and Teng (1998) claimed that even in the presence of strong trust between two parties, the explicitly-stipulated contract is necessary.

297 And the empirical evidence seems to favor this view (Luo 2002a; Ryall and Sampson 2009).

298 As prior interactions increase, contracting cost reduces and including boilerplate or common terms in new contracts almost entails no cost. But, if without control provisions, the increasing the likelihood of opportunistic behavior would augment the potential losses from misbehavior (Crocker and Reynolds 1993). Consequently, partners even with previous experience would rather include more specific and detailed control provisions. Therefore, partners' in-role behavior is ensured with a lower probability of incompliance.

Contractual control is deduced to have negative effects on extra-role behavior but prior interactions would breed more extra-role behavior and more control provisions. It implies that there is a multi-path effect of prior interactions on extra-role behavior. Extra-role behavior can be discouraged by the mediating effect of contract control while stimulated through other paths, for example, trust. Thus, we develop the following hypotheses:

Hypothesis 5: Prior interactions are positively associated with contractual control.

$310 \quad$ Hypothesis 6: Contractual control mediates the relationship between prior interactions and 311 (a) in-role behavior and (b) extra-role behavior.

312 As for the effects of prior interactions on contractual coordination and adaptation, 313 investigation into the different source of performance risk could give a delicate explanation.

314 First consider contractual coordination provisions which are designed against performance 315 risk originated from task interdependence and project complexity. From the perspective of 316 deliberate learning efforts (Ryall and Sampson 2009; Poppo et al. 2008), partners who have 317 prior interactions are more likely to establish learning process (Arino and Reuer 2004). They identify, synthesize, and disseminate their knowledge about their partner or transaction into the subsequent contracts in order to improve alliance outcomes (Poppo and Zenger 2002; Mellewigt et al. 2012). Repeated ineractions deepen partners' understanding of each other's management style and troubleshooting procedures (Buvik and Rolfsen 2015; Reuer and Arino 
2007). They become more skilled at drafting provisions to avoid "honest mistakes" caused by miscommunication (Mayer and Argyres 2004). These knowledge would formalize as contractual clauses in subsequent contracts (Arino and Reuer 2004). Inter-organizational routines developed over time would also formalize as new contractual clauses. As learning efforts is partner-specific, a particular transaction between partners can largely benefit coordination (Mellewigt et al. 2012). Meanwhile, the boilerplate effects induce subsequent contracts to include boilerplate or common coordination clauses of previous contracts, thereby the complexity of contractual coordination is increased. As a result, partners will be more informed about how to conduct cooperative behavior. Thus, we develop the following hypotheses:

Hypothesis 7: Prior interactions are positively associated with contractual coordination.

Hypothesis 8: Contractual coordination mediates the relationship between prior interactions and (a) in-role behavior and (b) extra-role behavior.

Regarding to the relationship of prior interactions and contractual adaptation, previous identifying what contingencies to consider (Mayer and Argyres 2004; Mayer and Bercovitz 2008), and that prior ties led to the establishment of strategies that could respond to challenges similar to what they had experienced before (Buvik and Rolfsen 2015). In contrast with this viewpoint, we expect that prior interactions between two firms don't necessarily add to contractual adaptation. Contractual adaptation clauses are needed in case of unanticipated construction industry. Such disturbances are independent of the focal collaboration anticipate the changeable future. The reason is that adaptation clauses are not specific to a particular partner, thus it is difficult to learn from prior experience directly like the way coordination clauses do. On the other hand, even such external environmental disturbances 
can be anticipated, the cost of drafting more detailed contracts about those contingencies and response measures is high. Complexity of contractual adaptation may well doesn't remarkably increase, as a result of weighing ex ante contracting cost against the benefits it will bring. Thus, we develop the following hypothesis:

Hypothesis 9: Prior interactions are unrelated with contractual adaptation.

Hypotheses 10: Contractual adaptation doesn't mediate the relationship between prior interactions and (a) in-role behavior and (b) extra-role behavior.

The overall research framework of this study is presented in Fig. 1.

[Insert Fig. 1 about here]

\section{Methods}

\subsection{Sampling and Data Collection}

This study obtained data through a questionnaire survey. The respondents are all project professionals from Chinese contracting enterprises in the top 250 contractors list of 2015 year published by $\mathrm{ENR}^{1}$. All the respondents were required to fill in the questionnaires according to the details of one recently completed project, to ensure the accuracy of information. To reduce social desirability bias, respondents were also informed that there's no right or wrong answers (Podsakoff et al. 2003), and the questionnaires were confidential and to be used solely for academic research. Additionally, respondents were promised attractive gifts to encourage their participation in our survey.

The survey lasted over six months and 580 questionnaires were distributed. We finally obtained 261 questionnaires, representing a response rate of $45.0 \%$. After deleting record with missing or unmatched data, 200 valid records were selected, representing an effective response rate of $34.5 \%$. Descriptive statistics for the sample are presented in Table 1.

\footnotetext{
${ }^{1}$ ENR: Engineering News-Record. The website: http://www.enr.com/.
} 
As Table 1 illustrates, among the sample, the respondents with over 5 years work experience account for $65.5 \%$, which indicates that respondents overall have a good understanding of their work contents and are able to make accurate judgments. The percentage of managerial level, including project managers and department managers, accounts for $69.0 \%$, which implies that respondents are well informed about project. The types of projects surveyed include kinds of construction projects, which ensure the randomness of the sample and reduce the interference of characteristics of certain type of projects. Additionally, there are considerable variance in the value of prior interactions, which is $34.0 \%$ partners with long-term cooperation, $27.5 \%$ with not much cooperation experience and $38.5 \%$ with none cooperation experience.

Considering potential bias resulting from different work experience, we conducted an independent-sample $t$-test to compare answers from less-experienced respondents (work experience $<5$ years) and more-experienced respondents (work experience $\geq 5$ years). As shown in Table 2, all $\mathrm{p}$ values of Levene's test are well above 0.05 , which means that variance of all variables are homogeneous. And then, all $\mathrm{p}$ values of $t$-test are above 0.05 , which indicates mean of all variables are homogeneous. Thus, there is no significant difference between less-experienced respondents and more-experienced respondents.

All items in the questionnaire were completed by contractors, which includes contractor's self-assessment of cooperative behavior. To check the threat of common method bias resulting from using a single data source, Harman's one-factor test was conducted. Items of multi-item variables were entered into the factor analysis with principal components analysis, 
using varimax rotation. The results show that there are five factors whose eigenvalues are greater than 1 . These five factors could explain $71.578 \%$ of the total variance; and there is no one factor which can explain more than the benchmark, $30 \%$ of the total variance. It means that neither a single factor nor a general factor can account for the majority of the covariance in these variables. Common method variance is not significant in this study.

\subsection{Measures}

407 Measures in this study were adapted or developed from previous relevant research. The measuring items are all originally written in English or derived from English literature, translated into Chinese, and then translated back into English by a different translator, to conduct a dual check for accuracy. To ensure the face validity, the questionnaire was pretested with 20 representatives who undertake construction project management. Based on their responses, items wording was modified to enhance clarity (Hair et al. 2006). All the items, unless specifically otherwise indicated, were measured with a seven-point Likert scale

414 (1=strongly disagree; $7=$ strongly agree).

\section{5}

\subsubsection{Dependent Variable: Cooperative Behavior}

Because in construction projects, most of work is done by contractors, the variable of “cooperative behavior" measures only contractors' cooperative behavior. Based on the work of Anvuur and Kumaraswamy (2012) and Kashyap and Sivadas (2012), we adapted three items to capture in-role behavior. For example, one item to measure in-role behavior is "the contractor adequately fulfills the responsibilities that are stipulated in the contract" at the organizational level, in line with "you fulfill the responsibilities specified in your job description" which assesses behaviors at the individual level (Anvuur and Kumaraswamy 2012). Another example is "the contractor meets the owner's expectations of project performance", which is similar to "your organization meets the performance expectations of its franchisor" (Kashyap and Sivadas 2012).

Likewise, we adapted another three items to capture extra-role behavior. As this concept originates from the individual level, the definition and measurement emphasize individuals' 
spontaneous and innovative behavior, such as "made innovative suggestions to help improve your work setting" (Anvuur and Kumaraswamy 2012). However, through the interviews with some respondents, we find they always feel confused about what are "innovative suggestions". Instead, "reasonable suggestions" is easier to understand. In fact, the reasonable suggestions made by contractors spontaneously just reflect their innovativeness, since innovation in construction project is mainly embodied in optimization of design and construction schemes. Based on characteristics and construction industry and feedback from respondents, we modify one item to "the contractor gives reasonable suggestions spontaneously, in order to help the owner".

\subsubsection{Independent Variables: Prior Interactions}

There are various measures to capture prior interactions in previous research, such as measuring it as a dummy variable to indicate the presence or absence of prior alliances (Reuer and Arino 2007), measuring it by the years that partners have cooperated. (Poppo et al. 2008). However, the dummy variable is unable to accurately capture the cooperation history, and measuring years is difficult for respondents to recall and doesn't fit in with the construction industry. Thus, this study measured "prior interactions" by the frequency of previous cooperation. The item is "How often is the prior cooperation between the owner and contractor: A. Long-term cooperation; B. Not too much cooperation experience; C. none cooperation experience".

\subsubsection{Mediating Variable: Contract}

The variable "contract" includes contractual control, contractual coordination, and contractual adaptation. Contractual control aims to limit partners' opportunism and reduce behavioral uncertainty, which is similar to Luo (2002b)'s contractual obligatoriness. Zhang et al. (2016) also measured contractual control in the construction project. Referring to the work by Luo (2002b) and Zhang et al. (2016), we adapted three items to capture contractual control. One sample item is "The contract stipulates severe economic punishment and penalization against the breaching party". 

literature. Referring to the coordinating methods proposed from ASCE (2000) and the definition of contractual coordination, three items were developed. One sample item is "The contract specifies reporting procedures during the process of the project". Luo (2002b) have measured in general industry context. Referring to the work by Luo 461 (2002b), three items, after wording modifications, are adapted fit in with the construction project context. One sample item is "The contract provides principles or guidelines for handling force majeure".

464 The measuring items of main variables are listed full in Table 3.

\subsubsection{Control Variables}

In order to eliminate other factors' interference, several control variables, including project duration, project contract price, and the affiliation relationship of the owner and contractor, were selected. First, the attributes of projects would exert interferences on governance design (Luo 2005). We thus controlled project attributes, including project duration and contract price. Second, the affiliation relationship existing between owners and contractors is a typical phenomenon in China. We measured the affiliation relationship as a dummy variable to indicate the presence or absence of the affiliation: $1=$ affiliation and $0=$ non-affiliation.

\section{[Insert Table 3 about here]}

\subsection{Reliability and Validity Analysis}

Because measuring items in this study are adapted or developed but not directly from extant literature, we conducted an exploratory factor analysis (EFA) to check the structure validity of these items. EFA with principal components analyses, using varimax rotation was computed on SPSS 19.0 for all the items from multi-item variables. As presented in Table 4, items have clean loadings on their respective variables and loadings are all above the 0.5 
benchmark. It indicated that these items can represent their variables well.

$$
\text { [Insert Table } 4 \text { about here] }
$$

To assess the reliability of items, internal consistency test was performed in SPSS 19.0. As shown in Table 3, the Cronbach's alpha values range from 0.699 to 0.843 , which are above or very close to the 0.7 benchmark. It indicates that these items have sufficient and satisfactory internal consistency and reliability (Andrews and Robinson 1991).

To assess the convergent validity of measures, average variance extracted (AVE) and construct reliability (CR) were examined with aid of AMOS 21.0. As shown in Table 3, the AVE values range from 0.488 to 0.644 , which are above or very close to the 0.5 benchmark. The CR values range from 0.725 to 0.844 , all above the 0.7 benchmark. These values indicate a good convergent validity of every variable's items. Additionally, to test the discriminant validity, the square roots of AVE are compared with the off-diagonal correlation coefficients. As illustrated in Table 5, the square roots of the AVE are all greater than the off-diagonal correlations, demonstrating a good discriminant validity.

\section{[Insert Table 5 about here]}

\section{Analyses and Results}

Multiple regression analyses were conducted to examine the hypotheses. For the sake of potential multi-collinearity, values of the variance inflation factors (VIF) were checked in SPSS 19.0. The VIF for every regression equation ranges from 1.005 to 1.408 , well below the rule-of-thumb cutoff of 10 (Netter et al. 1974). It indicates there's no sizable multi-collinearity among independent variables and control variables.

\subsection{Basic Hypothesis Analyses}

The regression results were reported in Table $6 . \mathrm{H} 1$ concerning effects of prior interactions 
on cooperative behavior was tested in Model 1. M1(a) and M1(c) show that prior interactions have significant positive effects on in-role behavior $(\beta=0.386, p<0.001)$ and extra-role behavior $(\beta=0.290, \mathrm{p}<0.01)$. Thus, H1a and H1b are supported.

$\mathrm{H} 2, \mathrm{H} 3$ and $\mathrm{H} 4$ about effects of the contract on cooperative behavior were tested in Model

1. As presented in M1(b), contractual control $(\beta=0.138, \mathrm{p}<0.05)$, coordination $(\beta=0.141, \mathrm{p}<$ $0.05)$ and adaptation $(\beta=0.148, \mathrm{p}<0.05)$ are all positively related to in-role behavior, indicating that $\mathrm{H} 2 \mathrm{a}, \mathrm{H} 3 \mathrm{a}$ and $\mathrm{H} 4 \mathrm{a}$ are supported. In $\mathrm{M} 1(\mathrm{~d})$, contractual coordination $(\beta=0.163$, $\mathrm{p}<0.05)$ and adaptation $(\beta=0.185, \mathrm{p}<0.01)$ are demonstrated to be positively related to extra-role behavior, but contractual control $(\beta=-0.081, \mathrm{p}>0.05)$ have no significant effects on extra-role behavior. Hence, $\mathrm{H} 3 \mathrm{~b}$ and $\mathrm{H} 4 \mathrm{~b}$ are supported but $\mathrm{H} 2 \mathrm{~b}$ is rejected.

The effects of prior interactions on the contract were also tested in Model 2. M2(f) shows that prior interactions have significant positive effects on contractual coordination $(\beta=0.263$, $\mathrm{p}<0.01)$. In $\mathrm{M} 2(\mathrm{e})$ and $\mathrm{M} 2(\mathrm{~g})$, prior interactions are demonstrated to have no significant effects on contractual control $(\beta=0.127, \mathrm{p}>0.05)$ and adaptation $(\beta=0.079, \mathrm{p}>0.05)$. Thus, $\mathrm{H} 7$ and $\mathrm{H} 9$ are supported but $\mathrm{H} 5$ is rejected.

\section{[Insert Table 6 about here]}

\subsection{Mediation Hypothesis Analyses}

To test the mediation of the contract, this study followed the procedures suggested by

Baron and Kenny (1986):

Step 1. Test the coefficient $c$ between the independent variables and the dependent variable, if $c$ was significant, go on the next step.

Step 2. Test the coefficient $a$ between the independent variables and the mediator.

Step 3. Add the independent variables and the mediator as the predictors of the dependent variables, and test the coefficient $b$ between the mediator and the dependent variable and the coefficient $c^{\prime}$ between the independent variables and the dependent variable. If $a$ and $b$ were 
both significant, while c' was not significant, the full mediation effect is verified; otherwise,

the partial mediation effect is verified. If neither $a$ nor $b$ was significant, there is no mediation effect.

539 These three steps have been conducted in 4.1 Basic Hypothesis Analyses and the coefficients are summarized in Table 7.

541

\section{[Insert Table 7 about here]}

As shown in Table 7, all coefficient $c$ are significant, and step 1 is satisfied. Turning to step 2, coefficient $a$ of H8a and H8b are significant but others aren't significant. As for step 3, firstly, coefficient $a$ and $b$ of H8a and H8b are both significant, and coefficient $c$ ' are also significant. Therefore, H8a and H8b are supported and contractual coordination has a partial mediating role.

However, coefficient $a$ and $b$ of H6b aren't significant. So contractual control doesn't mediate the relationship between prior interactions and extra-role behavior and H6b is rejected.

Coefficient $a$ of H6a, H10a and H10b aren't significant but their coefficient $b$ are significant. If $a$ or $b$ was significant, the Sobel test (Sobel 1982) is needed. Sobel test was conducted on Free Statistics Calculators $4.0^{2}$ and the results are shown in Table 7. As shown in Table 7, H6a is rejected but H10a and H10b are supported $(\mathrm{p}=0.118,0.220,0.218$, all above 0.05$)$. Contractual control and adaptation don't have mediating roles.

For the convenience of the readers, the test results of all the hypotheses are listed in Table 8.

\section{[Insert Table 8 about here]}

\footnotetext{
${ }^{2}$ Free Statistics Calculators 4.0: http://www.danielsoper.com/statcalc/default.aspx. The website has been used more than 40 million times and citied in more than 1,300 scientific papers. 
In summary, the results support that prior interactions and contracts are important to facilitate cooperative behavior in construction projects and also verify the mediating role of contractual coordination.

\section{5. Discussion and Conclusions}

566

\subsection{Discussion}

As predicted in $\mathrm{H} 1 \mathrm{a}$ and $\mathrm{H} 1 \mathrm{~b}$, prior interactions are empirically verified to facilitate contractors' in-role behavior and extra-role behavior. Prior interactions foster inter-partner trust (Gulati 1995), increase mutual understanding (Lumineau and Henderson 2012), and establish normative routines (Arino and Reuer 2004) between owners and contractors. The owners' trusting in contractors motivates contractors to fulfill their work in return. Mutual understanding helps contractor to understand what owners want. And normative routines (Heide and John 1992) exert pressure on contractors to make them to behave as owners expected. Moreover, a good reputation built in prior interactions is likely to encourage contractors to take extra work (Das and Teng 1998) to preserve or promote the good reputation. The findings suggest the importance of prior interactions in construction projects. The real-life construction projects are different from what conventional view labels as “one-off and discrete project". It is, actually, consistent with the sociologists' emphasis on the transaction's interconnectedness and social environment (Granovetter 1985).

However, given the important role of contracts in inter-organizational cooperation, there are two contrary views on the issue of how contract affects cooperative behavior, one of which believes there is a positive effect for the reason that the specified role and responsibilities and economic punishment and penalization against the breaching will prevent parties from opportunistic behavior (Luo 2002a, Poppo and Zenger 2002), while the other one argues that too much monitoring and penalty clauses release a low-trust signal and it will strengthen the opportunism behavior tendency instead (Ghoshal and Moran 1996; Bernheim and Whinston 1998). Our results suggest that different contractual functions have nuanced 
effects on different cooperative behavior. In construction projects, the typical traits of covert behavior and performance observation difficulties create a fertile environment for contractors' opportunism (Zhou and Xu 2012; Zhang et al. 2016). Contractual control is crucial to reduce exchange hazards. Thus $\mathrm{H} 2 \mathrm{a}$ is supported. However, the empirical results show that contractual control has no effects on extra-role behavior. As contractual control strengthens, it restrains contractors' behavior only within the scope of contract (Lumineau and Quélin 2012).

594 The extra-role behavior obviously exceeds the contract scope, so control provisions are less likely to affect extra-role behavior. In previous literature, it is argued that increased control signals a lack of trust. However, Lumineau (2014) argued that the lack of trust doesn't necessarily signify distrust and it doesn't necessarily damage the relationship between owners and contractors. Thus, contractual control doesn't have negative effects on contractors' extra-role behavior.

Consistent with the dominant views, $\mathrm{H} 3 \mathrm{a}$ and $\mathrm{H} 3 \mathrm{~b}$ indicate that contractual coordination

601 facilitates contractors' in-role and extra-role behavior. Previous research also suggests that 602 coordination is the critical aspect of successful projects and participants with capabilities of applying appropriate coordination methods tend to achieve good performance (Chang and Shen 2009). The concurrent tasks and multiple interfaces intertwining construction projects make coordination clauses become necessary. Coordination clauses are helpful to avoid or reduce misunderstanding or missteps. The communication channels built through coordination clauses are also good for improving relationship of owners and contractors and increasing probability of contractors' voluntarily taking extra work. Consequently, contractual coordination facilitates contractors' in-role and extra-role behavior.

Due to the project complexity and long-term duration, construction projects are exposed to a very turbulent environment. Contractual adaptation is just like a buffer layer to protect contractors from hard landing to the future uncertainty. The well-designed adaptation

613 provisions also indicate a promising future. It nourishes the cooperative environment and promotes contractors' in-role and extra-role behavior. These findings provide a more nuanced 
picture on contractual governance and also extend the understanding of Transaction Cost Economics' intention of designing contracts.

617 Moreover, prior literature also gives bewildering evidence on the relationships between 618 prior interactions and contract. One stream of the literature departs from a learning effect standpoint and insists that prior exchange experience between the same partners makes the subsequent contract more detailed (Poppo and Zenger 2002; Mayer and Argyres, 2004; Ryall and Sampson 2009). On the contrary, some scholars discover that contracts are less complex when firms have allied with each other previously (Reuer and Arino 2007). One cause of these divergent views is that most previous studies measure contract complexity as a whole, failing to distinguish the different effect of prior interactions on different dimensions of contract. In view of this, we conduct the research on different contractual functions and the results may provide some interesting insights.

First, prior interactions have no significant effects on control provisions based on the result of H5. It is inconsistent with Ryall and Sampson (2009)'s finding that partners with prior 629 deals would include more monitoring provisions in the new contract. The cause may be that 630 Ryall and Sampson coded some coordinating contents as monitoring provisions, such as “... conduct periodic reviews “.with written reports $\cdots "$ "(Ryall and Sampson 2009: 912). Another plausible reason is that control provisions often serve as boilerplate but not for partner-specific purpose, so they seldom change with collaboration experience (Luo 2002). Although prior interactions have no significant positive effects on control provisions, it at least implies that partners who have cooperated before wouldn't reduce provisions for control purpose. Despite the presence of trust, the fragile and unstable trust still hardly substitutes for contract. If the transaction requires, partners would still come up with a highly specified contract.

Second, the positive effect of prior interactions on contractual coordination has been confirmed. Consistent with previous research (Mellewigt et al. 2012), prior ties between the same partners reinforce the use of contractual provisions aiming at 'coordination'. This fact 
also complies with the view that prior relationships between firms can stimulate the development of inter-organizational routines, independent of trust (Reuer and Arino 2007).

644 The dyadic partner relationship can be seen as a system, and the performance risk caused by miscommunication across working interface between organizations and task complexity is within the system. Therefore, contracts become repositories about collaborations governance

647 (Mayer and Argyres, 2004).Differently, the experience on how to deal with environment uncertainties is not partner-specific. The exogenous disturbance is beyond system formed by the two parties. That's why prior interactions also have no significant effects on contractual adaptation. This result is inconsistent with previous research. Moreover, compared with previous research in other industries, this study is set in the construction context. Every project in the construction industry is idiosyncratic ( $\mathrm{Lu}$ et al. 2015), which may cause a diversity of unanticipated changes. Adaptation provisions may be specific to every construction project. The project-dependent lessons and previously-used adaptation provisions maybe don't fit in with subsequent projects. Hence, prior interactions don't have significant effects on contractual adaptation.

657 With regard to the mediating role of the contract, the results support H8 that contractual coordination mediates prior interactions and two types of cooperative behavior, and H10 that contractual adaptation doesn't mediate the relationship between prior interactions and cooperative behavior. Drawing from the above discussion, the learning effects from prior interactions trigger more detailed contracts coordination provisions. Formalized normative routines and clear reporting procedures in new contracts enable contractors to achieve more cooperative behavior.

\section{$664 \quad 5.2$ Conclusions and Implications}

This study attempts to examine the effects of prior interactions on in-role and extra-role behavior and the mediating role of contract in construction projects, providing a nuanced explanation on the determinants of cooperative behavior from a multi-dimensional perspective on contract. Using a sample of 200 contractors from Chinese construction 
industry, we have three main contributions. First, this study confirms previous findings on the positive effect of prior interactions on both in-role or extra-role cooperative behavior. Second, we elaborate distinct effects of three contractual functions on two type of cooperative behavior. It takes a holistic perspective on contractual functions (control, coordination and adaptation), and provides more fine-grain effects of contractual governance in construction projects. Third, this study provides new insights into the relationship between prior interactions and different contractual functions combined with different inter-organizational risk concerns, verifying the mediating role of contractual control.

This study also suggests managerial implications. It arouses construction practitioners' concurrent consciousness of prior interactions and contractual design. First, the importance of prior interactions in construction projects encourages practitioners to seek potential superior partners and maintain long-term relationship with them. And then, training can be provided to assist partners to acquire similar experience as what prior ties supply, such as mutual understanding and normative routines. Additionally, the effects of prior interactions on contractual design remind practitioners to inherit lessons from prior interactions and attach importance to the post-project assessment.

\subsection{Limitations and Future Research}

This study still has limitations that present avenues for future research to undertake. First, the measure of prior interactions focuses only on the quantity. To consider quantity and quality of prior interactions simultaneously would take a more comprehensive picture. Future research could consider the quantity and quality of prior interactions simultaneously. Second,

690 the assessment of contractor's cooperative behavior is self-report. The self-reporting information may be partial, although several means have been used to reduce the bias. Future research could be conducted through matching questionnaires of owners and contracts. Lastly, this study conducted on a sample of only Chinese construction projects. Different cultures and institutional environments are likely to alter the effects of prior interactions and contracts. Future research could be conducted in more broad settings to capture an international picture. 


\section{Acknowledgements}

697 This study was supported by the National Natural Science Foundation of China (NSFC) 698 under Grants No. 71231006 and 71572124. The authors would like to acknowledge the 699 financial support from NSFC and also thank the participation of all informants in the questionnaire survey. Additionally, the authors appreciate the helpful suggestions from all

701 reviewers and editor.

\section{References}

Andrews, F. M., Robinson, J. P., 1991. Measures of social psychological attitudes, Vol. 1, J. P. Robinson, P. R. Shaver, and L. S. Wrightsman, eds., Academic Press, San Diego, 61-114. Anvuur, A. M., Kumaraswamy, M. M., 2012. Measurement and antecedents of cooperation in construction. Journal of Construction Engineering and Management, 138(7), 797-810. Argyres, N., Mayer, K. J., 2007. Contract design as a firm capability: an integration of learning and transaction cost perspectives. Academy of Management Review, 32(4), 1060-1077.

Argyres, N. S., Bercovitz, J., Mayer, K. J., 2007. Complementarity and evolution of contractual provisions: An empirical study of IT services contracts. Organization

713 Science, 18(1), 3-19.

714 Arino, A. M., Reuer, J. J., 2004. Alliance contractual design. Barcelona, IESE Business School Working Paper No. 572.

716 ASCE, Quality in the Constructed Project: A Guide for Owners, Designers and Constructors, 717 2nd Ed., ASCE, Manuals and Reports on Engineering Practice No. 73, 2000.

718 Baron, R. M., Kenny, D. A., 1986. The moderator-mediator variable distinction in social 719 psychological research: Conceptual, strategic, and statistical considerations. Journal of 720 Personality and Social Psychology, 51(6), 1173.

721 Batenburg, R. S., Raub, W., Snijders, C., 2003. Contacts and contracts: dyadic embeddedness 
and the contractual behavior of firms. Research in the Sociology of Organizations, 20(1), 135-188.

Bernheim, B. D., Whinston, M. D., 1998. Incomplete contracts and strategic ambiguity. American Economic Review, 902-932.

Buvik, M. P., Rolfsen, M., 2015. Prior ties and trust development in project teams-A case study from the construction industry. International Journal of Project Management, 33(7), 1484-1494.

Cao, Z., Lumineau, F., 2015. Revisiting the interplay between contractual and relational governance: A qualitative and meta-analytic investigation. Journal of Operations Management, 33,15-42.

Chang, A. S., Shen, F. Y., 2009. Coordination needs and supply of construction projects. Engineering Management Journal, 21(4),44-57.

Crocker, K. J., Reynolds, K. J., 1993. The efficiency of incomplete contracts: an empirical analysis of air force engine procurement. RAND Journal of Economics, 24(1), 126-146.

Das, T. K., Teng, B. S., 1996. Risk types and inter-firm alliance structures. Journal of management studies, 33(6), 827-843.

Das, T. K., Teng, B. S., 1998. Between trust and control: Developing confidence in partner cooperation in alliances. Academy of Management Review, 23(3), 491-512.

Fu, Y. C., Chen, Y. Q., Zhang, S. B., Wang, W. Q., 2015. Promoting cooperation in construction projects: an integrated approach of contractual incentive and trust. Construction Management and Economics, 33(8), 653-670.

Ghoshal, S., Moran, P., 1996. Bad for practice: A critique of the transaction cost theory. Academy of management Review, 21(1), 13-47.

Gil, N., 2009. Developing cooperative project client-supplier relationships: How much to expect from relational contracts? California Management Review, 51(2), 144-169.

Granovetter, M., 1985. Economic action and social structure: The problem of embeddedness. American Journal of Sociology, 481-510. 
Gulati, R., 1995. Does familiarity breed trust? The implications of repeated ties for contractual choice in alliances. Academy of Management Journal, 38(1), 85-112.

Gulati, R., Singh, H., 1998. The architecture of cooperation: Managing coordination costs and appropriation concerns in strategic alliances. Administrative Science Quarterly, 781-814.

Hair, J. F., Black, W. C., Babin, B. J. Y. A., Anderson, R. E., and Tatham, R. L., 2006. Multivariate data analysis: Pearson Prentice Hall, Pearson Prentice Hall, Upper Saddle River,

\section{New Jersery.}

756 Heide, J. B., John, G., 1992. Do norms matter in marketing relationships? the Journal of Marketing, 32-44.

Hviid, M., 2000. Long-term contracts and relational contracts. Encyclopedia of Law and Economics, 40(10), 1228-1244.

Kashyap, V., Sivadas, E., 2012. An exploratory examination of shared values in channel relationships. Journal of Business Research, 65(5), 586-593.

Katz, D., 1964. The motivational basis of organizational behavior. Behavioral Science, 9(2), 131-146.

Kim, K. K., Park, S. H., Ryoo, S. Y., Park, S. K., 2010. Inter-organizational cooperation in buyer-supplier relationships: Both perspectives. Journal of Business Research, 63(8), 863-869.

Lu, Y. B., Luo, L., Wang, H. L., Le, Y., Shi, Q., 2015. Measurement model of project complexity for large-scale projects from task and organization perspective. International Journal of Project Management, 33(3), 610-622. Lui, S. S., Ngo, H. Y., 2004. The role of trust and contractual safeguards on cooperation in non-equity alliances. Journal of Management, 30(4), 471-485. Lumineau, F., Henderson, J. E., 2012. The influence of relational experience and contractual governance on the negotiation strategy in buyer-supplier disputes. Journal of Operations

774 Management, 30(5), 382-395. 
interfirm dispute resolution. Strategic Management Journal, 32(5), 532-555.

Lumineau, F., Quélin, B. V., 2012. An empirical investigation of inter-organizational opportunism and contracting mechanisms. Strategic Organization, 10(1), 55-84.

Lumineau, F., 2014. How Contracts Influence Trust and Distrust. Journal of Management, 0149206314556656

Luo, Y. D., 2002a. Contract, cooperation, and performance in international joint ventures. Strategic Management Journal, 23(10), 903-919.

Luo, Y. D., 2002b. Partnering with foreign firms: How do Chinese managers view the governance and importance of contracts ? Asia Pacific Journal of Management, 19(1), $127-151$

Luo, Y. D., 2005. Transactional characteristics, institutional environment and joint venture contracts. Journal of International Business Studies, 36(2), 209-230.

Luo, Y. D., 2008. Structuring inter-organizational cooperation: The role of economic integration in strategic alliances. Strategic Management Journal, 29(6), 617-637.

Macaulay, S., 1963. Non-contractual relations in business: A preliminary study. American Sociological Review, 55-67.

Malhotra, D., Lumineau, F., 2011. Trust and collaboration in the aftermath of conflict: The effects of contract structure. Academy of Management Journal, 54(5), 981-998.

Mayer, K. J., Argyres, N. S., 2004. Learning to contract: Evidence from the personal computer industry. Organization Science, 15(4), 394-410.

Mayer, K. J., \& Bercovitz, J., 2008. The influence of inertia on contract design: contingency planning in information technology services contracts. Managerail and Decision Economics, $29(2-3), 149-163$.

Mellewigt, T., Decker, J. P. D. C., Eckhard, B., 2012. What drives contract design in alliances? Taking stock and how to proceed. Zeitschrift für Betriebswirtschaft, 82(7-8), 839-864.

Netter, J., Wasserman, W., Kutner, M., 1974. Applied linear statistical models: Regression, 
analysis of variance, and experimental designs, Richard D. Irwin, Homewood, IL. Parkhe, A., 1993. Strategic alliance structuring: A game theoretic and transaction cost examination of interfirm cooperation. Academy of Management Journal, 36(4),794-829.

Podsakoff, P. M., MacKenzie, S. B., Lee, J. Y., Podsakoff, N. P., 2003. Common method biases in behavioral research: a critical review of the literature and recommended remedies. Journal of Applied Psychology, 88(5), 879.

Poppo, L., Zenger, T., 2002. Do formal contracts and relational governance function as substitutes or complements? Strategic Management Journal, 23(8),707-725.

Poppo, L., Zhou, K. Z., Ryu, S., 2008. "Alternative origins to inter-organizational trust: An interdependence perspective on the shadow of the past and the shadow of the future." Organization Science, 19(1), 39-55.

Reuer, J. J., Arino, A., 2007. Strategic alliance contracts: Dimensions and determinants of contractual complexity. Strategic Management Journal, 28(3),313.

Ryall, M. D., Sampson, R. C., 2003. Do prior alliances influence contract structure? Evidence from technology alliance contracts. Evidence from Technology Alliance Contracts (February 2003). Simon School of Business Working Paper No. FR, 03-11.

Ryall, M. D., Sampson, R. C., 2009. Formal contracts in the presence of relational enforcement mechanisms: Evidence from technology development projects. Management Science, 55(6), 906-925.

Salbu, S. R., 1997. Evolving contract as a device for flexible coordination and control. American Business Law Journal, 34(3), 329-384.

Schepker, D. J., W. Y., Martynov, A., Poppo, L., 2014. The many futures of contracts moving beyond structure and safeguarding to coordination and adaptation. Journal of Management, 40(1), 193-225.

Sobel, M. E., 1982. Asymptotic confidence intervals for indirect effects in structural equation models. Sociological Methodology, 13(1982), 290-312.

Susarla, A., Barua, A., Whinston, A. B., 2010. Multitask agency, modular architecture, and 
830 task disaggregation in SaaS. Journal of Management Information Systems, 26(4), 87-118.

831 Williamson, O. E., 1979. Transaction-cost economics: the governance of contractual 832 relations. Journal of Law and Economics, 233-261.

833 Williamson, O. E., 1985. The Economic Institutions of Capitalism, Free Press, New York

834 Woolthuis, R. K., Hillebrand, B., and Nooteboom, B., 2005. Trust, contract and relationship 835 development. Organization Studies, 26(6), 813-840.

836 Wuyts, S., 2007. Extra-role behavior in buyer-supplier relationships. International Journal of 837 Research in Marketing, 24(4), 301-311.

838 Zhang, S. B., Fu, Y. F., Gao, Y., Zheng, X. D., 2016. Influence of Trust and Contract on 839 Dispute Negotiation Behavioral Strategy in Construction Subcontracting. Journal of 840 Management in Engineering, 04016001.

841 Zhou, K. Z., Xu, D., 2012. How foreign firms curtail local supplier opportunism in China: 842 Detailed contracts, centralized control, and relational governance. Journal of International 843 Business Studies, 43(7), 677-692.

844 Ziegler, R., Schlett, C., 2016. An attitude strength and self-perception framework regarding 845 the bi-directional relationship of job satisfaction with extra-role and in-role behavior: The 846 doubly moderating role of work centrality. Frontiers in Psychology, 7, 235.

847 
3 Abstract:

\section{Do Prior Interactions Breed Cooperation in Construction Projects? The Mediating Role of Contracts}

There has long been inconsistence on the relationship among prior interactions, contracts and cooperative behavior. This study aims to examine how prior interactions affect cooperative behavior, including the effects of prior interactions on cooperative behavior and the mediating role of the contract between prior interactions and cooperative behavior. We classify cooperative behavior as in-role and extra-role behavior, and contract as a three-dimensional construct, including control, coordination and adaptation. Collecting data from 200 contractors in Chinese construction industry, the empirical results demonstrate the significance of the effect of prior interactions, the relationship between contract and cooperative behavior, and the mediating role of contractual coordination. According to our result, increasing contractual coordination emerge from prior interactions, while contractual control and adaptation is not related to these repeated collaborations. The findings reflect the interconnectedness of real-life projectsand provide a nuanced explanation to the complex relationships among prior interactions, contracts and cooperative behavior.

Keywords: construction project, inter-organizational relationship, prior interactions, contract, cooperative behavior.

\section{Introduction}

In construction industry, repeated transactions often take place between the same pair of owner and contractor. The emergent process resulting from prior ties is likely to alter subsequent governance design as well as partners' behavior (Poppo et al. 2008; Gulati 1995). Many believed that repeated exchanges generate trust and learning which make partners better able to deal with each other (Mayer and Argyres 2004; Ryall and Sampson 2009).

Thereby, we consider prior interactions may facilitate cooperative behavior. During the 
continuing interacting process there emerge alternative means to cope with cooperation risks. As mechanisms for achieving cooperation in inter-organizational transactions, contracts have been long regarded as formal governance to limit potential opportunism (Williamson 1985).

However, inconsistent evidence exists for the relationship among prior interactions, contracts and cooperative behavior. First, with respect to contracts and cooperative behavior, previous literature provides plenty of evidence on the positive relationship between the two. Some argue that contracts aims to clarifying partners' role and responsibilities (Luo, 2002a), developing trust and encouraging commitments (Poppo and Zenger 2002; Lui and Ngo 2004) such that idiosyncratic and deviant behavior will be alleviated and parties will perform in accordance with the mutual expectations (Salbu 1997). Consequently, cooperation is enhanced. In contrast, some scholars hold the opposite view that the use of contractual control signals distrust which is detrimental to cooperative relationship and even gives rise to opportunistic behavior that cannot be specified by contracts (Ghoshal and Moran 1996; Bernheim and Whinston 1998).

Second, there is also a growing debate on how contract design changes with repeated relationships (Ryall and Sampson 2009). Quite a few of studies indicates that contract may change with prior collaborative histories. Poppo and Zenger (2002) revealed that norms and social ties emerging from prior exchange would complement contractual governance. Ryall and Sampson (2003) focus on the effect of prior alliances on contract structure and find that contracts are more complete or detailed if firms have prior alliances with the same firm or other firms. Their subsequent study draws a further conclusion that a firm's contracts tend to be more detailed and more likely to include penalties when it engages in frequent deals, especially when the prior deals are between the same partners (Ryall and Sampson 2009). On the contrary, evidence from Reuer and Arino (2007) shows that more prior alliances between the partners would lead to less contractual complexity. The major point of contention lies in that whether contract can be substituted by trust and inter-organizational routines fostered in prior relationships or it will be more detailed due to learning effects which lower ex ante 
contracting costs (Mayer and Argyres 2004).

54 In our views, the conflicts among previous findings may be a consequence of insufficiency in dimension dividing of contract and cooperative behavior. Different contract provisions are

56 designed for different purposes. However, the global indicators of contractual complexity rather than particular provisions are often adopted as measurement of contract (Poppo and Zenger 2002). Similarly, cooperative behavior can also be viewed as a two-dimension construct, including in-role behavior and extra-role behavior (Katz 1964). Extra-role behavior is mostly discussed as organizational citizenship behavior at the individual level but is rarely mentioned at the transaction level, in spite of the fact that the firms can make extra efforts to enhance project performance besides completing the tasks specified in the contract. Thus, the global measurement can't distinguish the effects of certain factors on particular contractual provisions (Reuer and Arino 2007) as well as the effects of particular contractual provisions on certain type of cooperative behavior, which might result in confusion. We suggest that a better alternative is to investigate contract from a multi-functional perspective, namely

67 contractual control, coordination and adaption.

Based on observations and theories, we propose that prior interactions are likely to affect partners' cooperative behavior and contracts in construction projects. Moreover, from the

70 Transaction Cost Economics perspective (Williamson 1979), the contract fosters partners' cooperative behavior through reducing their opportunistic behavior. Relying on the effect, contracts may mediate prior interactions and contractors' cooperative behavior. Hence, this study develops a model to address the following research questions:

How do prior interactions affect cooperative behavior:

And 3) what effects do prior interactions have on the subsequent contract and does the contract mediate the effect of prior interactions on cooperative behavior?

The main contributions this study intended to offer are to explicate the nature of the linkage 
between the three functions of contract and the two types of cooperative behavior, and demonstrate the different paths through which prior interactions affect contract and cooperative behavior. Elaborating these more fine-grained effects can brings new explanation for previous controversy and offer some insight into the determinants of cooperative behavior. The remainder of this study is organized as follows. First, we review previous relevant literature and develop hypotheses. Second, we present the description of methodology and statistical results. And then, we have discussions on the results. Finally, we make conclusions and give managerial implications.

\section{Theoretical Foundation and Hypotheses}

\subsection{Cooperative Behavior}

Cooperation is a necessary ingredient for the success of construction projects. However, partners' cooperative behavior is not automatic or easily fostered (Malhotra and Lumineau 2011). Many efforts have been made to identify determinants of cooperation, but most of them consider cooperation as a general concept (Das and Teng 1998; Luo 2002a, 2002b), or measure it as performance (Luo 2008). Few studies distinguish different types of cooperative behavior. The seminal work of Katz (1964) proposes a two-dimensional construct of cooperative behavior, including in-role behavior and extra-role behavior. The in-role behavior refers to following mandatory rules or role descriptions. Obviously, the in-role behavior is the minimal level of standards for work. But if only relying on the minimal level behavior, organizations are difficult to operate effectively. Hence, it requires another type of behavior that is referred to as extra-role behavior. The extra-role behavior is the voluntary and spontaneous behavior, usually beyond the specified role descriptions. For example, the contractor may propose constructive suggestions for the project design document, or improve project value by a more appropriate project schedule.

The concepts of in-role and extra-role behavior derived from organization behavior field (Ziegler and Schlett 2016; Anvuur and Kumaraswamy 2012). Since the behavior of an 
organization is substantially done by its members, this classification can be reasonably extended to organizational level (Fu et al. 2015; Wuyts 2007). The applicability of the concept borrowing has been verified in the field of inter-organizational relationships

109 including construction projects, such as behavior of suppliers and buyers in the supply chain

110 (Kashyap and Sivadas 2012), or behavior of owners and contractors in construction projects

111 (Gil 2009). Due to the complexity of construction projects, only depending on the blueprints

112 of prescribed behavior would make projects very fragile and likely to breakdown. Actually,

113 partners' behavior usually tends to be composed of prescribed behavior and spontaneous

114 behavior. Thus, the concepts of in-role and extra-role behavior could better capture the reality

115 of behavior in construction projects.

\section{$116 \quad 2.2$ Contract}

117 Referring to inter-organizational cooperation, the contract is widely accepted as one

118 fundamental element to maintain inter-organizational relationship and reduce transaction

119 hazard. Scholars have presented two types of risks in inter-organizational relationships:

120 relational risk and performance risk (Das and Teng, 1996). According to Mellewigt et al.

121 (2012), relational risk relates to the hazards of partners' self-interested behavior. Such

122 non-cooperative behavior leads to the probability and consequences of unsatisfactory cooperation. However, there may exist performance risk (i.e. the hazards of unable to achieve

124 the performance objectives) even with full cooperation between transacting parties. On

125 account of different concerns of inter-organizational relationship risks, a three-function model

126 in contract studies is proposed, namely control, coordination and adaption (Mellewigt et al.

127 2012).

128 Relational risk is caused by potential opportunism and manifests in non-cooperative 129 behavior. Contracts provide an institutional framework for cooperation, within which partners 130 perform their rights and obligations (Gulati 1995). From Transaction Cost Economics 131 perspective, organizations use various contractual arrangements to safeguard investments 132 against misappropriation and reduce exchange hazards. Thus, contractual control provisions 
are designed to avoid relational risk. Control is the first function of the contract that has been recognized. In earlier and even contemporary literature, contracts are generally regarded as a uni-dimensional construct, which aim at controlling partner's opportunistic behavior.

Performance risk has two major sources. The first one is related to task interdependence and project complexity, which are prominent in construction projects. Contractual coordination clauses are designed to deal with this issue. Following previous research on analyses of contractual provisions (Parkhe 1993; Reuer and Arino 2007; Ryall and Sampson 2009), it is found that contracts serve for another purpose, that is, coordinating participants' behavior. Contractual coordination, through specifying task description (Argyres et al. 2007), interaction interfaces (Susarla et al. 2010), reporting procedures (Reuer and Arino 2007) and project milestones (Chang and Shen 2009), guides contractors to align actions with owners and achieve collective goals. Coordination provisions are particularly necessary when there are task interdependence and heterogeneous participants (Mellewigt et al. 2012). The former two dimensions of contracts focus on aligning partner's intentions or behavior, but construction projects are faced with risks not only from human variability but also environmental disturbances (Luo 2002a). Such unanticipated contingencies in the transaction environment are the second source of performance risk. Derived from future uncertainty and human bounded rationality (Williamson 1979), contracts also function as contingency adaptability to cope with unforeseen events in the future. Adaptation provisions aim at specifying principles or guidelines on how to handle unanticipated events that may arise during collaboration process (Schepker et al. 2014; Mellewigt et al. 2012). Especially in long-term projects, the increased possibility of encountering changes needs more governance flexibility to adapt to the future environment, avoiding breakdowns resulting from environmental disturbances.

Overall, for purpose of mitigating different risks in inter-organizational relationships, contracts serve as a three-functional instrument by limiting partners' opportunism, aligning each other's actions, and coping with future environmental uncertainty. The construct of 

consider three distinct contractual functions simultaneously (Lui and Ngo 2004; Salbu 1997;

162 Zhang et al. 2016). Hence, this study would take a holistic view to distinguish the effects of

163 three distinct contractual functions.

\subsection{Prior Interactions}

It is generally thought that economic transactions are discrete and one-off, especially the long-term construction projects, and the interconnectedness of transactions is often neglected (Batenburg et al. 2003), which means that transactions are regarded as independent and successive collaborative relationships between firms are ignored. Actually, sociologists have noticed the importance of prior interactions in economic transactions and emphasized that prior interactions would shape subsequent transactions governance or partners' behavior (Gulati 1995; Heide and John 1992). Some research has also implied the effects of prior interactions. Gulati and Singh (1998) contended that firms with prior ties are less likely to choose more hierarchical structure for their subsequent alliances. The trust developed over these prior ties may alleviate concerns of opportunism. Lumineau and Henderson (2012) found that partners who have cooperated before would rather adopt a cooperative negotiation strategy than a competitive strategy. Mellewigt et al. (2012) based on large amount of literature review advanced some propositions concerning the effects of prior interactions on contractual design and performance outcomes.

179 These evidences reinforce the importance of prior interactions. Cooperation experience is 180 likely to exert influences on subsequent transactions. However, due to the low transaction 181 frequency of construction industry, project interconnectedness doesn't receive sufficient attention. In extant literature, the effects of prior interactions in construction projects are sparsely noted. Therefore, this study would fill the gap to examine the effects of prior interactions in construction projects.

\subsection{Prior Interactions and Cooperative Behavior}

While many economics researchers often overlook prior interactions in economic 
transactions, sociologists address the existence of prior interactions and argue that economic exchange is embedded in social structure (Heide and John 1992). Gulati (1995) uses prior alliances as the proxy of trust. It indicates that the prior interactions foster inter-partner trust. The prior interactions often become overlaid with social content that carries strong expectations of trust and confidence in each other's intentions or behavior (Lui and Ngo 2004; Granovetter 1985). The increased interactions provide partners with opportunities to learn idiosyncrasies of each other, leading to high transaction efficiency. There may be inter-organizational routines developing through successive collaborations (Arino and Reuer 2004). These routines would motivate partners to conform to the each other's expectations and guide them to make commitments (Macaulay 1963).

Moreover, the long cooperation history also signals a positive reputation of partners. Out of the intention to preserve their good reputation, partners tend to make more commitments (Ryall and Sampson 2009). A longer transaction history could enhance the level and range of cooperation over time (Kim et al. 2010). Partners with long cooperation history would like to go extra miles to assure each other's satisfaction (Das and Teng 1998). Thus, we develop the following hypothesis:

Hypothesis 1: Prior interactions are positively associated with (a) in-role behavior and (b) extra-role behavior.

\subsection{Contract and Cooperative behavior}

When organizations enter one exchange, the biggest concern of them is the predictability of counterparty's behavior (Gulati 1995). The explicitly-stipulated contracts are devised to make partner's behavior predictable (Kazt 1964).

According to the behavioral assumption of Transaction Cost Economics, human have potential opportunism and tend to seek self-interest with guiles (Williamson 1985). The contract is an important mechanism by which one organization protects themselves from counterparty's opportunism (Cao and Lumineau 2015). With the aid of contractual provisions concerning controlling, it achieves to reduce opportunistic behavior and safeguard 
investments against misappropriation by the partner (Schepker et al. 2014).

215 Contract also set legal punishments and economic penalties for incompliance. Since the

216 threat of these severe punishments or penalties, partners would be encouraged to comply with

217 contractual agreement and other mandatory rules (Mellewigt et al. 2012; Lumineau and

218 Malhotra 2011). The greater complexity of contractual control is (i.e. the more inclusive and

219 specific contractual control provisions are), the more likely partners will fulfill their

220 prescribed tasks. Thus, we develop the following hypothesis:

221 Hypothesis 2a: Contractual control is positively associated with in-role behavior.

222 Contractual control limits partners' opportunistic behavior and facilitates in-role behavior.

223 However, as to the work beyond contractual requirements, contractual control may have a contrary effect on it.

225 Previous research has argued that contractual control may damage trust and ruin the cooperative relationships (Cao and Lumineau 2015), while another stream of studies holds the opposite view that based on the clearly-articulated contractual control makes partners build trust and then encourages more commitments (Poppo and Zenger 2002; Lui and Ngo 2004). One explanation to this contradictory may lie in effects of contractual control on different types of cooperative behavior. The effect of control provisions on in-role behavior has been deducted above - in fear of legal punishments and economic penalties, partners would perform what contracts stipulate. However, whether to fulfill extra-role behavior more depends on relationship between partners or willingness of partners, but is hardly manipulated by contractual control provisions. The increased number and stringency of contractual control provisions signals a lack of trust, which is detrimental to relationship quality between partners. In this case, partners are less likely to take innovative and spontaneous activities beyond their work scope. Thus, we develop the following hypothesis:

238 Hypothesis 2b: Contractual control is negatively associated with extra-role behavior.

239 Contractual control focuses on negative aspects of human variability, while contractual coordination focuses on the positive aspect of how to align partners' action and achieve 
collective goals (Lumineau and Malhotra 2011). Coordination clauses describe tasks interfaces (Argyres and Mayer 2007), reporting procedures and regular meetings (Reuer and Arino 2007), and project schedule and milestones (Schepker et al. 2014; Chang and Shen 2009).

Contractual coordination is particularly necessary when a transaction is characterized by a high degree of task interdependence and heterogeneous participants (Mellewigt et al. 2012).

247 Coordination-oriented provisions are intended to mitigate the risks of misunderstanding and missteps that might disrupt cooperative behavior. Lumineau and Malhotra (2011)'s study suggested that the greater contractual coordination would improve information exchange and cooperation. Through guiding partners to "what we want to achieve and how" (Woolthuis et al. 2005), contractual coordination ensures partners' shared understanding of the relationship (Lumineau and Malhotra 2011) and facilitates goal congruence between partners (Chang and Shen 2009).

Furthermore, coordination provisions support various forms of communication, such as reporting, regular meeting and so on. These appropriate linkages between partners breed high trust (Malhotra and Lumineau 2011). Once trust has been established between partners, partners tend to take an active part in work, and even undertake voluntarily the extra tasks. Thus, we develop the following hypothesis:

Hypothesis 3: Contractual coordination is positively associated with (a) in-role behavior and (b) extra-role behavior.

While the former two dimensions of contracts are intended to respond to human variability, contracts also serve the third function to cope with environmental uncertainty. Because of future uncertainty and human bounded rationality, it is impossible to write a complete contract which can foresee all possible events in the future (Williamson 1979). To avoid being vulnerable to environmental risks, contractual adaptation specifies principles or guidelines on how to handle unanticipated events during the collaboration process ( Schepker et al. 2014; Mellewigt et al. 2012). 

proceed, which ensures partners to feel relieved to make commitment. Generally speaking,

270 there would include more adaptation provisions in the long-term contract, because the

271 long-term transactions are likely to be disturbed by more changes (Hviid 2000). Preparing alternatives or respond principles in advance would reduce the possibility of severe loss or breakdowns of transactions (Luo 2002b).

274 The well-designed adaptation provisions indicate partners' intentions on continuing and completing transactions (Das and Teng 1998), which would motivate each other to undertake more works voluntarily.

Hypothesis 4: Contractual adaptation is positively associated with (a) in-role behavior and (b) extra-role behavior.

\section{$279 \quad 2.6$ Prior Interactions and Contract}

280 Contractual design is influenced by the extent that the partners have known each other (Luo 281 2002a). Previous research has debated over the effects of prior interactions on subsequent contract. For example, Reuer and Arino (2007) show that prior ties would lead to less contractual complexity; whereas Poppo and Zenger (2002) reveal that norms and social ties emerging from prior exchange would complement contractual governance. The conflicting findings may be a consequence of different measurement in previous research. For example, Reuer and Arino (2007) measure prior ties as a dummy variable just indicate the presence or absence of prior alliances. Poppo and Zenger (2002) regarded contract as a uni-dimensional construct and used one global item to measure it. This study measures prior interactions by the frequency of previous cooperation (see 3.2 Measures below), as well as distinguishes between contractual control, coordination and adaptation. In awareness of these distinct contractual functions, the effects of prior interactions on contracts should be reinterpreted. contract. Some scholars claimed that the development of trust or inter-organizational routines from past relationships would substitute control provisions, thus leading to less contractual 
control (Reuer and Arino 2007). However, Das and Teng (1998) claimed that even in the presence of strong trust between two parties, the explicitly-stipulated contract is necessary. And the empirical evidence seems to favor this view (Luo 2002a; Ryall and Sampson 2009). As prior interactions increase, contracting cost reduces and including boilerplate or common terms in new contracts almost entails no cost. But, if without control provisions, the increasing the likelihood of opportunistic behavior would augment the potential losses from misbehavior (Crocker and Reynolds 1993). Consequently, partners even with previous experience would rather include more specific and detailed control provisions. Therefore, partners' in-role behavior is ensured with a lower probability of incompliance.

Contractual control is deduced to have negative effects on extra-role behavior but prior interactions would breed more extra-role behavior and more control provisions. It implies that there is a multi-path effect of prior interactions on extra-role behavior. Extra-role behavior can be discouraged by the mediating effect of contract control while stimulated through other paths, for example, trust. Thus, we develop the following hypotheses:

Hypothesis 5: Prior interactions are positively associated with contractual control. Thus, contractual

Hypothesis 6: Contractual control mediates the relationship between prior interactions and (a) in-role behavior and (b) extra-role behavior.

As for the effects of prior interactions on contractual coordination and adaptation, investigation into the different source of performance risk could give a delicate explanation.

315 First consider contractual coordination provisions which are designed against performance risk originated from task interdependence and project complexity. From the perspective of deliberate learning efforts (Ryall and Sampson 2009; Poppo et al. 2008), partners who have prior interactions are more likely to establish learning process (Arino and Reuer 2004). They identify, synthesize, and disseminate their knowledge about their partner or transaction into the subsequent contracts in order to improve alliance outcomes (Poppo and Zenger 2002; Mellewigt et al. 2012). Repeated ineractions deepen partners' understanding of each other's 

2007). They become more skilled at drafting provisions to avoid "honest mistakes" caused by miscommunication (Mayer and Argyres 2004). These knowledge would formalize as contractual clauses in subsequent contracts (Arino and Reuer 2004). Inter-organizational routines developed over time would also formalize as new contractual clauses. As learning efforts is partner-specific, a particular transaction between partners can largely benefit coordination (Mellewigt et al. 2012). Meanwhile, the boilerplate effects induce subsequent contracts to include boilerplate or common coordination clauses of previous contracts, thereby the complexity of contractual coordination is increased. As a result, partners will be more informed about how to conduct cooperative behavior. Thus, we develop the following hypotheses:

Hypothesis 67: Prior interactions are positively associated with contractual coordination. Thus, contractual

Hypothesis 8: Contractual coordination mediates the relationship between prior interactions and (a) in-role behavior and (b) extra-role behavior.

Regarding to the relationship of prior interactions and contractual adaptation, previous literature suggest that contracting experience enables partners to develop the abilities of identifying what contingencies to consider (Mayer and Argyres 2004; Mayer and Bercovitz 2008), and that prior ties led to the establishment of strategies that could respond to challenges similar to what they had experienced before (Buvik and Rolfsen 2015). In contrast with this viewpoint, we expect that prior interactions between two firms don't necessarily add to contractual adaptation. Contractual adaptation clauses are needed in case of unanticipated contingencies, which are mostly derived from external environmental disturbances in construction industry. Such disturbances are independent of the focal collaboration relationship. On the one hand, there are so many contingencies in the inconstant transaction environment, and the mere relying on prior experience between partners is not enough to anticipate the changeable future. The reason is that adaptation clauses are not specific to a 
particular partner, thus it is difficult to learn from prior experience directly like the way coordination clauses do. On the other hand, even such external environmental disturbances can be anticipated, the cost of drafting more detailed contracts about those contingencies and response measures is high. Complexity of contractual adaptation may well doesn't remarkably increase, as a result of weighing ex ante contracting cost against the benefits it will bring. Thus, we develop the following hypothesis:

Hypothesis 79: Prior interactions are unrelated with contractual adaptation.-Thus, contractuat

Hypotheses 10: Contractual adaptation doesn't mediate the relationship between prior interactions and (a) in-role behavior and (b) extra-role behavior.

The overall research framework of this study is presented in Fig. 1.

[Insert Fig. 1 about here]

\section{Methods}

\subsection{Sampling and Data Collection}

This study obtained data through a questionnaire survey. The respondents are all project professionals from Chinese contracting enterprises in the top 250 contractors list of 2015 year published by ENR ${ }^{1}$. All the respondents were required to fill in the questionnaires according to the details of one recently completed project, to ensure the accuracy of information. To reduce social desirability bias, respondents were also informed that there's no right or wrong answers (Podsakoff et al. 2003), and the questionnaires were confidential and to be used solely for academic research. Additionally, respondents were promised attractive gifts to encourage their participation in our survey.

The survey lasted over six months and 580 questionnaires were distributed. We finally

\footnotetext{
${ }^{1}$ ENR: Engineering News-Record. The website: http://www.enr.com/.
} 
obtained 261 questionnaires, representing a response rate of $45.0 \%$. After deleting record with missing or unmatched data, 200 valid records were selected, representing an effective response rate of 34.5\%. Descriptive statistics for the sample are presented in Table 1.

\section{[Insert Table 1 about here]}

As Table 1 illustrates, among the sample, the respondents with over 5 years work experience account for $65.5 \%$, which indicates that respondents overall have a good understanding of their work contents and are able to make accurate judgments. The percentage of managerial level, including project managers and department managers, accounts for $69.0 \%$, which implies that respondents are well informed about project. The types of projects surveyed include kinds of construction projects, which ensure the randomness of the sample and reduce the interference of characteristics of certain type of projects. Additionally, there are considerable variance in the value of prior interactions, which is $34.0 \%$ partners with long-term cooperation, $27.5 \%$ with not much cooperation experience and $38.5 \%$ with none cooperation experience.

Considering potential bias resulting from different work experience, we conducted an independent-sample $t$-test to compare answers from less-experienced respondents (work experience $<5$ years) and more-experienced respondents (work experience $\geq 5$ years). As shown in Table 2, all p values of Levene's test are well above 0.05 , which means that variance of all variables are homogeneous. And then, all $\mathrm{p}$ values of $t$-test are above 0.05 , which indicates mean of all variables are homogeneous. Thus, there is no significant difference between less-experienced respondents and more-experienced respondents.

\section{[Insert Table 2 about here]}

All items in the questionnaire were completed by contractors, which includes contractor's 
self-assessment of cooperative behavior. To check the threat of common method bias resulting from using a single data source, Harman's one-factor test was conducted. Items of multi-item variables were entered into the factor analysis with principal components analysis, using varimax rotation. The results show that there are five factors whose eigenvalues are greater than 1 . These five factors could explain $71.578 \%$ of the total variance; and there is no one factor which can explain more than the benchmark, $30 \%$ of the total variance. It means that neither a single factor nor a general factor can account for the majority of the covariance in these variables. Common method variance is not significant in this study.

\section{$409 \quad 3.2$ Measures}

410 Measures in this study were adapted or developed from previous relevant research. The measuring items are all originally written in English or derived from English literature, translated into Chinese, and then translated back into English by a different translator, to conduct a dual check for accuracy. To ensure the face validity, the questionnaire was pretested with 20 representatives who undertake construction project management. Based on their responses, items wording was modified to enhance clarity (Hair et al. 2006). All the items, unless specifically otherwise indicated, were measured with a seven-point Likert scale

417 (1=strongly disagree; $7=$ strongly agree).

\subsubsection{Dependent Variable: Cooperative Behavior}

Because in construction projects, most of work is done by contractors, the variable of “cooperative behavior" measures only contractors' cooperative behavior. Based on the work of Anvuur and Kumaraswamy (2012) and Kashyap and Sivadas (2012), we adapted three items to capture in-role behavior. For example, one item to measure in-role behavior is "the contractor adequately fulfills the responsibilities that are stipulated in the contract" at the organizational level, in line with "you fulfill the responsibilities specified in your job description" which assesses behaviors at the individual level (Anvuur and Kumaraswamy 2012). Another example is "the contractor meets the owner's expectations of project 
its franchisor" (Kashyap and Sivadas 2012).

Likewise, we adapted another three items to capture extra-role behavior. As this concept originates from the individual level, the definition and measurement emphasize individuals' spontaneous and innovative behavior, such as "made innovative suggestions to help improve your work setting" (Anvuur and Kumaraswamy 2012). However, through the interviews with some respondents, we find they always feel confused about what are "innovative suggestions". Instead, "reasonable suggestions" is easier to understand. In fact, the reasonable suggestions made by contractors spontaneously just reflect their innovativeness, since innovation in construction project is mainly embodied in optimization of design and construction schemes. Based on characteristics and construction industry and feedback from respondents, we modify one item to "the contractor gives reasonable suggestions spontaneously, in order to help the owner".

\subsubsection{Independent Variables: Prior Interactions}

There are various measures to capture prior interactions in previous research, such as measuring it as a dummy variable to indicate the presence or absence of prior alliances (Reuer and Arino 2007), measuring it by the years that partners have cooperated. (Poppo et al. 2008). However, the dummy variable is unable to accurately capture the cooperation history, and measuring years is difficult for respondents to recall and doesn't fit in with the construction industry. Thus, this study measured "prior interactions" by the frequency of previous cooperation. The item is "How often is the prior cooperation between the owner and contractor: A. Long-term cooperation; B. Not too much cooperation experience; C. none cooperation experience".

\subsubsection{Mediating Variable: Contract}

The variable "contract" includes contractual control, contractual coordination, and contractual adaptation. Contractual control aims to limit partners' opportunism and reduce behavioral uncertainty, which is similar to Luo (2002b)'s contractual obligatoriness. Zhang et al. (2016) also measured contractual control in the construction project. Referring to the work 
by Luo (2002b) and Zhang et al. (2016), we adapted three items to capture contractual control.

One sample item is "The contract stipulates severe economic punishment and penalization against the breaching party".

There were no measuring items available to capture contractual coordination in extant literature. Referring to the coordinating methods proposed from ASCE (2000) and the definition of contractual coordination, three items were developed. One sample item is "The contract specifies reporting procedures during the process of the project”.

Contractual adaptation is devised to cope with unanticipated events in the future, which Luo (2002b) have measured in general industry context. Referring to the work by Luo (2002b), three items, after wording modifications, are adapted fit in with the construction project context. One sample item is "The contract provides principles or guidelines for handling force majeure".

The measuring items of main variables are listed full in Table 3.

\subsubsection{Control Variables}

In order to eliminate other factors' interference, several control variables, including project duration, project contract price, and the affiliation relationship of the owner and contractor, were selected. First, the attributes of projects would exert interferences on governance design (Luo 2005). We thus controlled project attributes, including project duration and contract price. Second, the affiliation relationship existing between owners and contractors is a typical phenomenon in China. We measured the affiliation relationship as a dummy variable to indicate the presence or absence of the affiliation: $1=$ affiliation and $0=$ non-affiliation.

\section{[Insert Table 3 about here]}

\subsection{Reliability and Validity Analysis}

Because measuring items in this study are adapted or developed but not directly from extant literature, we conducted an exploratory factor analysis (EFA) to check the structure 
validity of these items. EFA with principal components analyses, using varimax rotation was computed on SPSS 19.0 for all the items from multi-item variables. As presented in Table 4, items have clean loadings on their respective variables and loadings are all above the 0.5 benchmark. It indicated that these items can represent their variables well.

\section{[Insert Table 4 about here]}

To assess the reliability of items, internal consistency test was performed in SPSS 19.0. As shown in Table 3, the Cronbach's alpha values range from 0.699 to 0.843 , which are above or very close to the 0.7 benchmark. It indicates that these items have sufficient and satisfactory internal consistency and reliability (Andrews and Robinson 1991).

To assess the convergent validity of measures, average variance extracted (AVE) and construct reliability (CR) were examined with aid of AMOS 21.0. As shown in Table 3, the AVE values range from 0.488 to 0.644 , which are above or very close to the 0.5 benchmark. The CR values range from 0.725 to 0.844 , all above the 0.7 benchmark. These values indicate a good convergent validity of every variable's items. Additionally, to test the discriminant validity, the square roots of AVE are compared with the off-diagonal correlation coefficients. As illustrated in Table 5, the square roots of the AVE are all greater than the off-diagonal correlations, demonstrating a good discriminant validity.

\section{[Insert Table 5 about here]}

\section{Analyses and Results}

Multiple regression analyses were conducted to examine the hypotheses. For the sake of potential multi-collinearity, values of the variance inflation factors (VIF) were checked in SPSS 19.0. The VIF for every regression equation ranges from 1.005 to 1.408 , well below the rule-of-thumb cutoff of 10 (Netter et al. 1974). It indicates there's no sizable 
multi-collinearity among independent variables and control variables.

\subsection{Basic Hypothesis Analyses}

The regression results were reported in Table 6 . $\mathrm{H} 1$ concerning effects of prior interactions on cooperative behavior was tested in Model 1. M1(a) and M1(c) show that prior interactions have significant positive effects on in-role behavior $(\beta=0.386, \mathrm{p}<0.001)$ and extra-role behavior $(\beta=0.290, \mathrm{p}<0.01)$. Thus, H1a and H1b are supported.

$\mathrm{H} 2, \mathrm{H} 3$ and $\mathrm{H} 4$ about effects of the contract on cooperative behavior were tested in Model 1. As presented in $\mathrm{M} 1(\mathrm{~b})$, contractual control $(\beta=0.138, \mathrm{p}<0.05)$, coordination $(\beta=0.141, \mathrm{p}<$ $0.05)$ and adaptation $(\beta=0.148, \mathrm{p}<0.05)$ are all positively related to in-role behavior, indicating that $\mathrm{H} 2 \mathrm{a}, \mathrm{H} 3 \mathrm{a}$ and $\mathrm{H} 4 \mathrm{a}$ are supported. In $\mathrm{M} 1(\mathrm{~d})$, contractual coordination $(\beta=0.163$, $\mathrm{p}<0.05)$ and adaptation $(\beta=0.185, \mathrm{p}<0.01)$ are demonstrated to be positively related to extra-role behavior, but contractual control $(\beta=-0.081, p>0.05)$ have no significant effects on extra-role behavior. Hence, $\mathrm{H} 3 \mathrm{~b}$ and $\mathrm{H} 4 \mathrm{~b}$ are supported but $\mathrm{H} 2 \mathrm{~b}$ is rejected.

The effects of prior interactions on the contract were also tested in Model 2. M2(f) shows that prior interactions have significant positive effects on contractual coordination $(\beta=0.263$, $\mathrm{p}<0.01)$. In M2(e) and M2(g), prior interactions are demonstrated to have no significant effects on contractual control $(\beta=0.127, p>0.05)$ and adaptation $(\beta=0.079, p>0.05)$. Thus, $\underline{\mathrm{H} 7}$ and $\mathrm{H} 9$ are supported but $\mathrm{H} 5$ is rejected.

\section{[Insert Table 6 about here]}

\subsection{Mediation Hypothesis Analyses}

To test the mediation of the contract, this study followed the procedures suggested by Baron and Kenny (1986):

Step 1. Test the coefficient $c$ between the independent variables and the dependent variable, if $c$ was significant, go on the next step.

Step 2. Test the coefficient $a$ between the independent variables and the mediator. 

variables, and test the coefficient $b$ between the mediator and the dependent variable and the coefficient $c^{\prime}$ between the independent variables and the dependent variable. If $a$ and $b$ were both significant, while c' was not significant, the full mediation effect is verified; otherwise, the partial mediation effect is verified. If neither $a$ nor $b$ was significant, there is no mediation effect.

These three steps have been conducted in 4.1 Basic Hypothesis Analyses and the coefficients are summarized in Table 7.

As shown in Table 7, all coefficient $c$ are significant, and step 1 is satisfied. Turning to step $b$ are significant. If $a$ or $b$ was significant, the Sobel test (Sobel 1982) is needed. Sobel test was conducted on Free Statistics Calculators $4.0^{2}$ and the results are shown in Table 7. As shown in Table 7, H5ㅁa is rejected but $\mathrm{H} 7 \underline{10} \mathrm{a}$ and $\mathrm{H} 7 \underline{10 \mathrm{~b}}$ are supported $(\mathrm{p}=0.118,0.220$, 0.218, all above 0.05$)$. Contractual control and adaptation don't have mediating roles. $\underline{8}$

\footnotetext{
2 Free Statistics Calculators 4.0: http://www.danielsoper.com/statcalc/default.aspx. The website has been used more than 40 million times and citied in more than 1,300 scientific papers.
} 
565 In summary, the results support that prior interactions and contracts are important to

566 facilitate cooperative behavior in construction projects and also verify the mediating role of 567 contractual coordination.

\section{5. Discussion and Conclusions}

\section{$569 \quad 5.1$ Discussion}

570 As predicted in $\mathrm{H} 1 \mathrm{a}$ and $\mathrm{H} 1 \mathrm{~b}$, prior interactions are empirically verified to facilitate contractors' in-role behavior and extra-role behavior. Prior interactions foster inter-partner trust (Gulati 1995), increase mutual understanding (Lumineau and Henderson 2012), and establish normative routines (Arino and Reuer 2004) between owners and contractors. The owners' trusting in contractors motivates contractors to fulfill their work in return. Mutual understanding helps contractor to understand what owners want. And normative routines (Heide and John 1992) exert pressure on contractors to make them to behave as owners expected. Moreover, a good reputation built in prior interactions is likely to encourage contractors to take extra work (Das and Teng 1998) to preserve or promote the good reputation. The findings suggest the importance of prior interactions in construction projects.

580 The real-life construction projects are different from what conventional view labels as

581 "one-off and discrete project". It is, actually, consistent with the sociologists' emphasis on the transaction's interconnectedness and social environment (Granovetter 1985).

However, given the important role of contracts in inter-organizational cooperation, there are two contrary views on the issue of how contract affects cooperative behavior, one of which believes there is a positive effect for the reason that the specified role and responsibilities and economic punishment and penalization against the breaching will prevent parties from opportunistic behavior (Luo 2002a, Poppo and Zenger 2002), while the other one 
argues that too much monitoring and penalty clauses release a low-trust signal and it will strengthen the opportunism behavior tendency instead (Ghoshal and Moran 1996; Bernheim and Whinston 1998). Our results suggest that different contractual functions have nuanced effects on different cooperative behavior. In construction projects, the typical traits of covert behavior and performance observation difficulties create a fertile environment for contractors' opportunism (Zhou and Xu 2012; Zhang et al. 2016). Contractual control is crucial to reduce exchange hazards. Thus $\mathrm{H} 2 \mathrm{a}$ is supported. However, the empirical results show that contractual control has no effects on extra-role behavior. As contractual control strengthens, it restrains contractors' behavior only within the scope of contract (Lumineau and Quélin 2012). The extra-role behavior obviously exceeds the contract scope, so control provisions are less likely to affect extra-role behavior. In previous literature, it is argued that increased control signals a lack of trust. However, Lumineau (2014) argued that the lack of trust doesn't necessarily signify distrust and it doesn't necessarily damage the relationship between owners and contractors. Thus, contractual control doesn't have negative effects on contractors' extra-role behavior.

Consistent with the dominant views, $\mathrm{H} 3 \mathrm{a}$ and $\mathrm{H} 3 \mathrm{~b}$ indicate that contractual coordination facilitates contractors' in-role and extra-role behavior. Previous research also suggests that coordination is the critical aspect of successful projects and participants with capabilities of applying appropriate coordination methods tend to achieve good performance (Chang and Shen 2009). The concurrent tasks and multiple interfaces intertwining construction projects make coordination clauses become necessary. Coordination clauses are helpful to avoid or reduce misunderstanding or missteps. The communication channels built through coordination clauses are also good for improving relationship of owners and contractors and increasing probability of contractors' voluntarily taking extra work. Consequently, contractual coordination facilitates contractors' in-role and extra-role behavior.

613 Due to the project complexity and long-term duration, construction projects are exposed to

614 a very turbulent environment. Contractual adaptation is just like a buffer layer to protect 
contractors from hard landing to the future uncertainty. The well-designed adaptation provisions also indicate a promising future. It nourishes the cooperative environment and

617 promotes contractors' in-role and extra-role behavior. These findings provide a more nuanced 618 picture on contractual governance and also extend the understanding of Transaction Cost 619 Economics' intention of designing contracts.

620 Moreover, prior literature also gives bewildering evidence on the relationships between 621 prior interactions and contract. One stream of the literature departs from a learning effect standpoint and insists that prior exchange experience between the same partners makes the subsequent contract more detailed (Poppo and Zenger 2002; Mayer and Argyres, 2004; Ryall and Sampson 2009). On the contrary, some scholars discover that contracts are less complex when firms have allied with each other previously (Reuer and Arino 2007). One cause of these divergent views is that most previous studies measure contract complexity as a whole, failing to distinguish the different effect of prior interactions on different dimensions of contract. In view of this, we conduct the research on different contractual functions and the results may provide some interesting insights.

630 First, prior interactions have no significant effects on control provisions based on the result 631 of H5. It is inconsistent with Ryall and Sampson (2009)'s finding that partners with prior 632 deals would include more monitoring provisions in the new contract. The cause may be that 633 Ryall and Sampson coded some coordinating contents as monitoring provisions, such as “... conduct periodic reviews “.with written reports ..." (Ryall and Sampson 2009: 912). Another plausible reason is that control provisions often serve as boilerplate but not for partner-specific purpose, so they seldom change with collaboration experience (Luo 2002). Although prior interactions have no significant positive effects on control provisions, it at least implies that partners who have cooperated before wouldn't reduce provisions for control purpose. Despite the presence of trust, the fragile and unstable trust still hardly substitutes for contract. If the transaction requires, partners would still come up with a highly specified contract. 

confirmed. Consistent with previous research (Mellewigt et al. 2012), prior ties between the same partners reinforce the use of contractual provisions aiming at 'coordination'. This fact also complies with the view that prior relationships between firms can stimulate the development of inter-organizational routines, independent of trust (Reuer and Arino 2007).

647 The dyadic partner relationship can be seen as a system, and the performance risk caused by 648 miscommunication across working interface between organizations and task complexity is within the system. Therefore, contracts become repositories about collaborations governance

650 (Mayer and Argyres, 2004).Differently, the experience on how to deal with environment uncertainties is not partner-specific. The exogenous disturbance is beyond system formed by the two parties. That's why prior interactions also have no significant effects on contractual adaptation. This result is inconsistent with previous research. Moreover, compared with previous research in other industries, this study is set in the construction context. Every project in the construction industry is idiosyncratic ( $\mathrm{Lu}$ et al. 2015), which may cause a diversity of unanticipated changes. Adaptation provisions may be specific to every construction project. The project-dependent lessons and previously-used adaptation provisions maybe don't fit in with subsequent projects. Hence, prior interactions don't have significant effects on contractual adaptation.

660 With regard to the mediating role of the contract, the results support H $6 \underline{8}$ that contractual coordination mediates prior interactions and two types of cooperative behavior, and $\mathrm{H} 7 \underline{10}$ that contractual adaptation doesn't mediate the relationship between prior interactions and cooperative behavior. Drawing from the above discussion, the learning effects from prior interactions trigger more detailed contracts coordination provisions. Formalized normative routines and clear reporting procedures in new contracts enable contractors to achieve more cooperative behavior.

\section{7}

\subsection{Conclusions and Implications}

This study attempts to examine the effects of prior interactions on in-role and extra-role 
behavior and the mediating role of contract in construction projects, providing a nuanced explanation on the determinants of cooperative behavior from a multi-dimensional perspective on contract. Using a sample of 200 contractors from Chinese construction industry, we have three main contributions. First, this study confirms previous findings on the positive effect of prior interactions on both in-role or extra-role cooperative behavior. Second, we elaborate distinct effects of three contractual functions on two type of cooperative behavior. It takes a holistic perspective on contractual functions (control, coordination and adaptation), and provides more fine-grain effects of contractual governance in construction projects. Third, this study provides new insights into the relationship between prior interactions and different contractual functions combined with different inter-organizational risk concerns, verifying the mediating role of contractual control.

This study also suggests managerial implications. It arouses construction practitioners' concurrent consciousness of prior interactions and contractual design. First, the importance of prior interactions in construction projects encourages practitioners to seek potential superior partners and maintain long-term relationship with them. And then, training can be provided to assist partners to acquire similar experience as what prior ties supply, such as mutual understanding and normative routines. Additionally, the effects of prior interactions on contractual design remind practitioners to inherit lessons from prior interactions and attach importance to the post-project assessment.

\section{$688 \quad 5.3$ Limitations and Future Research}

This study still has limitations that present avenues for future research to undertake. First,

690 the measure of prior interactions focuses only on the quantity. To consider quantity and quality of prior interactions simultaneously would take a more comprehensive picture. Future research could consider the quantity and quality of prior interactions simultaneously. Second,

693 the assessment of contractor's cooperative behavior is self-report. The self-reporting information may be partial, although several means have been used to reduce the bias. Future research could be conducted through matching questionnaires of owners and contracts. Lastly, 
this study conducted on a sample of only Chinese construction projects. Different cultures and institutional environments are likely to alter the effects of prior interactions and contracts. Future research could be conducted in more broad settings to capture an international picture.

699

700

701

\section{Acknowledgements}

This study was supported by the National Natural Science Foundation of China (NSFC) under Grants No. 71231006 and 71572124 . The authors would like to acknowledge the financial support from NSFC and also thank the participation of all informants in the questionnaire survey. Additionally, the authors appreciate the helpful suggestions from all reviewers and editor.

\section{References}

Andrews, F. M., Robinson, J. P., 1991. Measures of social psychological attitudes, Vol. 1, J. P. Robinson, P. R. Shaver, and L. S. Wrightsman, eds., Academic Press, San Diego, 61-114. Anvuur, A. M., Kumaraswamy, M. M., 2012. Measurement and antecedents of cooperation in construction. Journal of Construction Engineering and Management, 138(7), 797-810.

Argyres, N., Mayer, K. J., 2007. Contract design as a firm capability: an integration of learning and transaction cost perspectives. Academy of Management Review, 32(4), 1060-1077.

Argyres, N. S., Bercovitz, J., Mayer, K. J., 2007. Complementarity and evolution of contractual provisions: An empirical study of IT services contracts. Organization Science, 18(1), 3-19.

Arino, A. M., Reuer, J. J., 2004. Alliance contractual design. Barcelona, IESE Business School Working Paper No. 572.

ASCE, Quality in the Constructed Project: A Guide for Owners, Designers and Constructors, 2nd Ed., ASCE, Manuals and Reports on Engineering Practice No. 73, 2000.

Baron, R. M., Kenny, D. A., 1986. The moderator-mediator variable distinction in social 
psychological research: Conceptual, strategic, and statistical considerations. Journal of Personality and Social Psychology, 51(6), 1173.

Batenburg, R. S., Raub, W., Snijders, C., 2003. Contacts and contracts: dyadic embeddedness and the contractual behavior of firms. Research in the Sociology of Organizations, 20(1), 135-188.

Bernheim, B. D., Whinston, M. D., 1998. Incomplete contracts and strategic ambiguity. American Economic Review, 902-932.

Buvik, M. P., Rolfsen, M., 2015. Prior ties and trust development in project teams-A case study from the construction industry. International Journal of Project Management, 33(7), 1484-1494.

Cao, Z., Lumineau, F., 2015. Revisiting the interplay between contractual and relational governance: A qualitative and meta-analytic investigation. Journal of Operations Management, 33,15-42.

Chang, A. S., Shen, F. Y., 2009. Coordination needs and supply of construction projects. Engineering Management Journal, 21(4),44-57.

Crocker, K. J., Reynolds, K. J., 1993. The efficiency of incomplete contracts: an empirical analysis of air force engine procurement. RAND Journal of Economics, 24(1), 126-146.

Das, T. K., Teng, B. S., 1996. Risk types and inter-firm alliance structures. Journal of management studies, 33(6), 827-843.

Das, T. K., Teng, B. S., 1998. Between trust and control: Developing confidence in partner cooperation in alliances. Academy of Management Review, 23(3), 491-512.

Fu, Y. C., Chen, Y. Q., Zhang, S. B., Wang, W. Q., 2015. Promoting cooperation in construction projects: an integrated approach of contractual incentive and trust. Construction Management and Economics, 33(8), 653-670.

Ghoshal, S., Moran, P., 1996. Bad for practice: A critique of the transaction cost theory. Academy of management Review, 21(1), 13-47.

Gil, N., 2009. Developing cooperative project client-supplier relationships: How much to 
expect from relational contracts? California Management Review, 51(2), 144-169.

Granovetter, M., 1985. Economic action and social structure: The problem of embeddedness. American Journal of Sociology, 481-510.

Gulati, R., 1995. Does familiarity breed trust? The implications of repeated ties for contractual choice in alliances. Academy of Management Journal, 38(1), 85-112.

Gulati, R., Singh, H., 1998. The architecture of cooperation: Managing coordination costs and appropriation concerns in strategic alliances. Administrative Science Quarterly, 781-814.

Hair, J. F., Black, W. C., Babin, B. J. Y. A., Anderson, R. E., and Tatham, R. L., 2006. Multivariate data analysis: Pearson Prentice Hall, Pearson Prentice Hall, Upper Saddle River, New Jersery.

Heide, J. B., John, G., 1992. Do norms matter in marketing relationships? the Journal of Marketing, 32-44.

Hviid, M., 2000. Long-term contracts and relational contracts. Encyclopedia of Law and Economics, 40(10), 1228-1244.

Kashyap, V., Sivadas, E., 2012. An exploratory examination of shared values in channel relationships. Journal of Business Research, 65(5), 586-593.

Katz, D., 1964. The motivational basis of organizational behavior. Behavioral Science, 9(2), 131-146.

Kim, K. K., Park, S. H., Ryoo, S. Y., Park, S. K., 2010. Inter-organizational cooperation in buyer-supplier relationships: Both perspectives. Journal of Business Research, 63(8), 863-869.

Lu, Y. B., Luo, L., Wang, H. L., Le, Y., Shi, Q., 2015. Measurement model of project complexity for large-scale projects from task and organization perspective. International Journal of Project Management, 33(3), 610-622.

Lui, S. S., Ngo, H. Y., 2004. The role of trust and contractual safeguards on cooperation in non-equity alliances. Journal of Management, 30(4), 471-485.

Lumineau, F., Henderson, J. E., 2012. The influence of relational experience and contractual 
governance on the negotiation strategy in buyer-supplier disputes. Journal of Operations Management, 30(5), 382-395.

Lumineau, F., Malhotra, D., 2011. Shadow of the contract: How contract structure shapes interfirm dispute resolution. Strategic Management Journal, 32(5), 532-555.

Lumineau, F., Quélin, B. V., 2012. An empirical investigation of inter-organizational opportunism and contracting mechanisms. Strategic Organization, 10(1), 55-84.

Lumineau, F., 2014. How Contracts Influence Trust and Distrust. Journal of Management, 0149206314556656 .

Luo, Y. D., 2002a. Contract, cooperation, and performance in international joint ventures. Strategic Management Journal, 23(10), 903-919.

Luo, Y. D., 2002b. Partnering with foreign firms: How do Chinese managers view the governance and importance of contracts ? Asia Pacific Journal of Management, 19(1), $127-151$.

Luo, Y. D., 2005. Transactional characteristics, institutional environment and joint venture contracts. Journal of International Business Studies, 36(2), 209-230.

Luo, Y. D., 2008. Structuring inter-organizational cooperation: The role of economic integration in strategic alliances. Strategic Management Journal, 29(6), 617-637.

Macaulay, S., 1963. Non-contractual relations in business: A preliminary study. American Sociological Review, 55-67.

Malhotra, D., Lumineau, F., 2011. Trust and collaboration in the aftermath of conflict: The effects of contract structure. Academy of Management Journal, 54(5), 981-998.

Mayer, K. J., Argyres, N. S., 2004. Learning to contract: Evidence from the personal computer industry. Organization Science, 15(4), 394-410.

Mayer, K. J., \& Bercovitz, J., 2008. The influence of inertia on contract design: contingency planning in information technology services contracts. Managerail and Decision Economics, 29(2-3), 149-163.

Mellewigt, T., Decker, J. P. D. C., Eckhard, B., 2012. What drives contract design in 
alliances? Taking stock and how to proceed. Zeitschrift für Betriebswirtschaft, 82(7-8), 839-864.

Netter, J., Wasserman, W., Kutner, M., 1974. Applied linear statistical models: Regression, analysis of variance, and experimental designs, Richard D. Irwin, Homewood, IL.

Parkhe, A., 1993. Strategic alliance structuring: A game theoretic and transaction cost examination of interfirm cooperation. Academy of Management Journal, 36(4),794-829.

Podsakoff, P. M., MacKenzie, S. B., Lee, J. Y., Podsakoff, N. P., 2003. Common method biases in behavioral research: a critical review of the literature and recommended remedies. Journal of Applied Psychology, 88(5), 879.

Poppo, L., Zenger, T., 2002. Do formal contracts and relational governance function as substitutes or complements? Strategic Management Journal, 23(8),707-725.

Poppo, L., Zhou, K. Z., Ryu, S., 2008. "Alternative origins to inter-organizational trust: An interdependence perspective on the shadow of the past and the shadow of the future." Organization Science, 19(1), 39-55.

Reuer, J. J., Arino, A., 2007. Strategic alliance contracts: Dimensions and determinants of contractual complexity. Strategic Management Journal, 28(3),313.

Ryall, M. D., Sampson, R. C., 2003. Do prior alliances influence contract structure? Evidence from technology alliance contracts. Evidence from Technology Alliance Contracts (February 2003). Simon School of Business Working Paper No. FR, 03-11.

Ryall, M. D., Sampson, R. C., 2009. Formal contracts in the presence of relational enforcement mechanisms: Evidence from technology development projects. Management Science, 55(6), 906-925.

Salbu, S. R., 1997. Evolving contract as a device for flexible coordination and control. American Business Law Journal, 34(3), 329-384.

Schepker, D. J., W. Y., Martynov, A., Poppo, L., 2014. The many futures of contracts moving beyond structure and safeguarding to coordination and adaptation. Journal of Management, 40(1), 193-225. 
830 Sobel, M. E., 1982. Asymptotic confidence intervals for indirect effects in structural equation models. Sociological Methodology, 13(1982), 290-312.

832 Susarla, A., Barua, A., Whinston, A. B., 2010. Multitask agency, modular architecture, and

833 task disaggregation in SaaS. Journal of Management Information Systems, 26(4), 87-118.

834 Williamson, O. E., 1979. Transaction-cost economics: the governance of contractual relations. Journal of Law and Economics, 233-261.

836 Williamson, O. E., 1985. The Economic Institutions of Capitalism, Free Press, New York

837 Woolthuis, R. K., Hillebrand, B., and Nooteboom, B., 2005. Trust, contract and relationship

838 development. Organization Studies, 26(6), 813-840.

839 Wuyts, S., 2007. Extra-role behavior in buyer-supplier relationships. International Journal of 840 Research in Marketing, 24(4), 301-311.

841 Zhang, S. B., Fu, Y. F., Gao, Y., Zheng, X. D., 2016. Influence of Trust and Contract on Dispute Negotiation Behavioral Strategy in Construction Subcontracting. Journal of Management in Engineering, 04016001.

844 Zhou, K. Z., Xu, D., 2012. How foreign firms curtail local supplier opportunism in China: Detailed contracts, centralized control, and relational governance. Journal of International Business Studies, 43(7), 677-692.

847 Ziegler, R., Schlett, C., 2016. An attitude strength and self-perception framework regarding the bi-directional relationship of job satisfaction with extra-role and in-role behavior: The doubly moderating role of work centrality. Frontiers in Psychology, 7, 235. 
Table 1. Demographic Characteristics of the Sample

\begin{tabular}{lll}
\hline Demographic variable & Value & $\%$ \\
\hline Work experience & $\geq 10$ years & 18.5 \\
& $5-10$ years & 47.0 \\
Professional qualifications & $<5$ years & 34.5 \\
& Project manager & 24.5 \\
& Department manager & 44.5 \\
Project type & General staff & 31.0 \\
& Housing & 26.5 \\
& Transportation & 20.5 \\
& Port and waterway & 13.0 \\
& Chemical and petrol & 3.5 \\
& Hydropower & 14.0 \\
& Telecommunication & 4.0 \\
& Municipal engineering & 13.5 \\
& Others & 5.0 \\
& Long-term cooperation & 34.0 \\
& Not too much cooperation experience & 27.5 \\
& none cooperation experience & 38.5 \\
\hline
\end{tabular}

Table 2. Independent-Sample $t$-Test Results

\begin{tabular}{|c|c|c|c|c|c|c|c|c|}
\hline \multirow{2}{*}{ Variable } & \multicolumn{3}{|c|}{$\begin{array}{l}\text { Levene's test for equality of } \\
\text { variance }\end{array}$} & \multicolumn{5}{|c|}{$t$-test for equality of means } \\
\hline & & $\mathrm{F}$ & Sig. & $\mathrm{t}$ & df & Sig. (two-tail) & $\begin{array}{l}\text { Mean } \\
\text { difference }\end{array}$ & $\begin{array}{l}\text { Standard } \\
\text { error } \\
\text { difference }\end{array}$ \\
\hline \multirow[t]{2}{*}{ PI } & Equal & 0.799 & 0.373 & 1.066 & 198.000 & 0.288 & 0.135 & 0.127 \\
\hline & Unequal & & & 1.048 & 132.169 & 0.296 & 0.135 & 0.129 \\
\hline \multirow{2}{*}{ CL } & Equal & 2.258 & 0.135 & -0.379 & 198.000 & 0.705 & -0.057 & 0.151 \\
\hline & Unequal & & & -0.399 & 159.707 & 0.690 & -0.057 & 0.143 \\
\hline \multirow{2}{*}{$\mathrm{CN}$} & Equal & 0.527 & 0.469 & 0.374 & 198.000 & 0.709 & 0.067 & 0.180 \\
\hline & Unequal & & & 0.374 & 139.111 & 0.709 & 0.067 & 0.180 \\
\hline \multirow{2}{*}{$\mathrm{CA}$} & Equal & 0.094 & 0.759 & -0.567 & 198.000 & 0.571 & -0.097 & 0.170 \\
\hline & Unequal & & & -0.552 & 128.342 & 0.582 & -0.097 & 0.175 \\
\hline \multirow{2}{*}{ IB } & Equal & 0.000 & 0.993 & -1.916 & 198.000 & 0.057 & -0.278 & 0.145 \\
\hline & Unequal & & & -1.890 & 133.078 & 0.061 & -0.278 & 0.147 \\
\hline \multirow{2}{*}{ EB } & Equal & 0.930 & 0.336 & 0.020 & 198.000 & 0.984 & 0.003 & 0.159 \\
\hline & Unequal & & & 0.021 & 158.793 & 0.983 & 0.003 & 0.151 \\
\hline
\end{tabular}

Note: PI: prior interactions; CL: contractual control; CN: contractual coordination; CA: contractual adaptation;

IB: in-role behavior; EB: extra-role behavior. 
Table 3. Measures Reliability and Validity Assessment

Construct and Measuring Items

Prior interactions

1. How often is the prior cooperation between the owner and contractor?

Contractual functions ( 1 = strongly disagree; $7=$ strongly agree )

Contractual control: $\quad \alpha=0.734 ; \mathrm{AVE}=0.488 ; \mathrm{CR}=0.739$

1. The contract stipulates strict clauses to prevent noncompliance.

2. The contract stipulates severe economic punishment and penalization against the breaching party.

3. The contract stipulates severe terms related to monitoring and controlling.

Contractual coordination: $\quad \alpha=0.843 ; \mathrm{AVE}=0.633 ; \mathrm{CR}=0.838$

1. The contract specifies reporting procedures during the process of the project.

2. The contract specifies detailed task execution procedures.

3. The contract provides the support for effective communication.

Contractual adaptation: $\quad \alpha=0.791 ; \mathrm{AVE}=0.571 ; \mathrm{CR}=0.799$

1. The contract provides principles or guidelines for handling force majeure.

2. The contract provides alternative solutions for responding to various contingencies that are likely to arise.

3. The contract stipulates provisions of variations and adjustments.

Cooperative behavior ( 1 = strongly disagree; $7=$ strongly agree $)$

In-role behavior: $\quad \alpha=0.838 ; \mathrm{AVE}=0.644 ; \mathrm{CR}=0.844$

1. The contractor adequately fulfills the responsibilities that are stipulated in the contract.

2. The contractor completes all the required works.

3. The contractor meets the owner's expectations of project performance.

Extra-role behavior: $\quad \alpha=0.699 ; \mathrm{AVE}=0.489 ; \mathrm{CR}=0.725$

1. The contractor participates actively in the works beyond contract requirements.

2. The contractor volunteers to undertake extra work beyond the scope of their work, to improve the project performance.

3. The contractor gives reasonable suggestions spontaneously, in order to help the owner.

Note: $\alpha=$ Cronbach's alpha; AVE = average variance extracted; $\mathrm{CR}=$ composite reliability. 
Table 4. Structure Validity of Measuring Items

\begin{tabular}{lccccc}
\hline Item & Factor 1 & Factor 2 & Factor 3 & Factor 4 & Factor 5 \\
\hline Contractual control & & & & & \\
Item 1 & $\mathbf{0 . 7 8 1}$ & 0.223 & 0.076 & 0.183 & -0.038 \\
Item 2 & $\mathbf{0 . 8 1 3}$ & 0.068 & 0.061 & 0.055 & -0.015 \\
Item 3 & $\mathbf{0 . 7 2 7}$ & 0.159 & 0.244 & 0.093 & 0.054 \\
Contractual coordination & & & & & \\
Item 1 & 0.102 & $\mathbf{0 . 8 5 5}$ & 0.218 & 0.126 & 0.081 \\
Item 2 & 0.159 & $\mathbf{0 . 8 0 8}$ & 0.157 & 0.038 & 0.194 \\
Item 3 & 0.222 & $\mathbf{0 . 8 0 2}$ & 0.111 & 0.218 & 0.016 \\
Contractual adaptation & & & & & \\
Item 1 & 0.079 & 0.256 & $\mathbf{0 . 7 6 8}$ & 0.044 & 0.092 \\
Item 2 & 0.123 & 0.122 & $\mathbf{0 . 8 7 9}$ & 0.021 & 0.080 \\
Item 3 & 0.185 & 0.089 & $\mathbf{0 . 7 5 3}$ & 0.278 & 0.071 \\
In-role behavior & & & & & \\
Item 1 & 0.013 & 0.137 & 0.105 & $\mathbf{0 . 8 7 4}$ & 0.097 \\
Item 2 & 0.204 & 0.066 & 0.150 & $\mathbf{0 . 8 5 6}$ & 0.099 \\
Item 3 & 0.136 & 0.193 & 0.051 & $\mathbf{0 . 7 3 0}$ & 0.243 \\
Extra-role behavior & & & & & \\
Item 1 & -0.015 & 0.167 & 0.158 & 0.220 & $\mathbf{0 . 8 1 4}$ \\
Item 2 & -0.049 & 0.108 & 0.049 & 0.025 & $\mathbf{0 . 8 8 5}$ \\
Item 3 & 0.082 & -0.019 & 0.041 & 0.395 & $\mathbf{0 . 5 1 2}$ \\
\hline
\end{tabular}

Table 5. Descriptive Statistics and Pearson Correlation Matrix

\begin{tabular}{cllllllllll}
\hline Variable & Mean & S.D. & 1 & 2 & 3 & 4 & 5 & 6 & 7 & 8 \\
\hline 1. IB & 5.629 & 0.980 & $\mathbf{0 . 8 0 3}$ & & & & & & \\
2. EB & 4.843 & 1.067 & $0.411^{* *}$ & $\mathbf{0 . 6 9 9}$ & & & & & \\
3. CL & 5.253 & 1.013 & $0.301^{* *}$ & 0.066 & $\mathbf{0 . 6 9 8}$ & & & & & \\
4. CN & 5.222 & 1.207 & $0.334^{* *}$ & $0.278^{* *}$ & $0.391^{* *}$ & $\mathbf{0 . 7 9 6}$ & & & & \\
5. CA & 5.203 & 1.142 & $0.300^{* *}$ & $0.249^{* *}$ & $0.340^{* *}$ & $0.411^{* *}$ & $\mathbf{0 . 7 5 5}$ & & & \\
6. PI & 1.955 & 0.852 & $0.299^{* *}$ & $0.235^{* *}$ & 0.087 & $0.168^{*}$ & 0.034 & & & \\
7. PD & 1.740 & 0.628 & -0.050 & 0.079 & -0.015 & $0.145^{*}$ & 0.093 & 0.109 & & \\
8. PCP & 2.240 & 0.696 & -0.014 & -0.105 & 0.050 & -0.044 & 0.006 & 0.086 & $0.442^{* *}$ \\
9. AR & 0.150 & 0.358 & -0.073 & 0.079 & -0.082 & -0.081 & $-0.149 *$ & $0.203 * *$ & 0.063 & -0.004
\end{tabular}

Note: IB: in-role behavior; EB: extra-role behavior; CL: contractual control; CN: contractual coordination; CA: contractual adaptation; PI: prior interactions; PD: project duration; PCP: project contract price; AR: affiliation relationship.

Boldface signifies that the values are greater than the off-diagonal correlations.

$* \mathrm{p}<.05 ; * * \mathrm{p}<.01 ; * * * \mathrm{p}<.001$. 
Table 6. Regression Analysis Results (N=200)

\begin{tabular}{|c|c|c|c|c|c|c|c|}
\hline \multirow{3}{*}{ Variable } & \multicolumn{4}{|c|}{ M1 } & \multicolumn{3}{|c|}{ M2 } \\
\hline & \multicolumn{2}{|c|}{ In-role behavior } & \multicolumn{2}{|c|}{ Extra-role behavior } & \multirow{2}{*}{$\begin{array}{c}\text { Contractual } \\
\text { control } \\
\text { (e) }\end{array}$} & \multirow{2}{*}{$\begin{array}{l}\text { Contractual coordination } \\
\text { (f) }\end{array}$} & \multirow{2}{*}{$\begin{array}{l}\text { Contractual adaptation } \\
\qquad(\mathrm{g})\end{array}$} \\
\hline & (a) & (b) & (c) & (d) & & & \\
\hline \multicolumn{8}{|l|}{ Control variable } \\
\hline \multirow{2}{*}{ Project duration } & -0.115 & -0.191 & 0.226 & 0.118 & -0.077 & 0.381 & 0.219 \\
\hline & $(-0.976)$ & $(-1.694)$ & (1.736) & $(0.913)$ & $(-0.598)$ & $(2.572)$ & $(1.530)$ \\
\hline \multirow{2}{*}{ Project contract price } & -0.015 & 0.022 & $-0.281^{*}$ & -0.216 & 0.090 & -0.256 & -0.087 \\
\hline & $(-0.142)$ & $(0.217)$ & $(-2.398)$ & $(-1.885)$ & $(0.777)$ & $(-1.923)$ & $(-0.679)$ \\
\hline Affiliation & -0.375 & -0.193 & 0.069 & 0.218 & -0.284 & -0.445 & -0.538 \\
\hline relationship & $(-1.984)$ & $(-1.084)$ & $(0.331)$ & $(1.068)$ & $(-1.385)$ & $(-1.874)$ & $(-2.345)$ \\
\hline \multicolumn{8}{|l|}{ Independent variable } \\
\hline Prior interactions & $0.386^{* * *}$ & $0.320 * * *$ & $0.290 * *$ & $0.243^{* *}$ & 0.127 & $0.263^{* *}$ & 0.079 \\
\hline 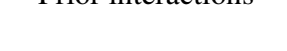 & $(4.844)$ & $(4.240)$ & (3.294) & $(2.816)$ & $(1.473)$ & $(2.623)$ & $(0.820)$ \\
\hline \multicolumn{8}{|l|}{ Mediating variable } \\
\hline \multirow{2}{*}{ Contractual control } & & $0.138^{*}$ & & -0.081 & & & \\
\hline & & $(2.017)$ & & $(-1.031)$ & & & \\
\hline \multirow{2}{*}{$\begin{array}{l}\text { Contractual } \\
\text { coordination }\end{array}$} & & $0.141 *$ & & $0.163 *$ & & & \\
\hline & & $(2.334)$ & & $(2.354)$ & & & \\
\hline \multirow{2}{*}{$\begin{array}{l}\text { Contractual } \\
\text { adaptation }\end{array}$} & & $0.148^{*}$ & & $0.185^{* *}$ & & & \\
\hline & & $(2.422)$ & & $(2.658)$ & & & \\
\hline $\mathrm{R}^{2}$ & 0.114 & 0.247 & 0.086 & 0.167 & 0.021 & 0.077 & 0.038 \\
\hline$\Delta \mathrm{R}^{2}$ & 0.096 & 0.219 & 0.067 & 0.137 & 0.001 & 0.058 & 0.018 \\
\hline $\mathrm{F}$ & $\begin{array}{c}6.279(4,195)^{*} \\
* *\end{array}$ & $\begin{array}{c}8.975(7,192)^{*} \\
* *\end{array}$ & $\begin{array}{c}4.591(4,195) \\
* *\end{array}$ & $\begin{array}{c}5.513(7,192)^{*} \\
* *\end{array}$ & $1.062(4,195)$ & $4.065(4,195)^{* *}$ & $1.922(4,195)$ \\
\hline
\end{tabular}

Note: $\quad * \mathrm{p}<.05 ; * * \mathrm{p}<.01 ; * * * \mathrm{p}<.001$ 
Table 7. Mediation Test Results

\begin{tabular}{lcccccccccc}
\hline Hypotheses & $\boldsymbol{c}$ & SEc & $\boldsymbol{a}$ & SEa & $\boldsymbol{b}$ & SEb & $\boldsymbol{c}^{\prime}$ & SEc' & $\begin{array}{c}\text { Sobel test } \\
\text { statistic }\end{array}$ & $\begin{array}{c}\text { Sig. } \\
\text { H6a }\end{array}$ \\
\hline 0.386*** & 0.080 & 0.127 & 0.087 & $0.138^{*}$ & 0.068 & 0.320 & 0.075 & 1.185 & 0.118 \\
H6b & $0.290^{* *}$ & 0.088 & 0.127 & 0.087 & -0.081 & 0.078 & 0.243 & 0.086 & $/$ & $/$ \\
H8a & $0.386^{* * *}$ & 0.080 & $0.263^{* *}$ & 0.100 & $0.141^{*}$ & 0.060 & $0.320^{* * *}$ & 0.075 & $/$ & $/$ \\
H8b & $0.290^{* *}$ & 0.088 & $0.263^{* *}$ & 0.100 & $0.163^{*}$ & 0.069 & $0.243 * *$ & 0.086 & $/$ & $/$ \\
H10a & $0.386^{* * *}$ & 0.080 & 0.079 & 0.097 & $0.148^{*}$ & 0.061 & 0.320 & 0.075 & 0.772 & 0.220 \\
H10b & $0.290^{* *}$ & 0.088 & 0.079 & 0.097 & $0.185^{* *}$ & 0.070 & 0.243 & 0.086 & 0.778 & 0.218 \\
\hline
\end{tabular}

Note: ${ }^{*} \mathrm{p}<.05 ; * * \mathrm{p}<.01 ; * * * \mathrm{p}<.001$.

SE: standard error.

Table 8. Test Results of Hypotheses

\begin{tabular}{ccc}
\hline Hypotheses & Supported & Not Supported \\
\hline H1a & $\sqrt{ }$ & \\
H1b & $\sqrt{ }$ & \\
H2a & $\sqrt{ }$ & $\sqrt{ }$ \\
H2b & & \\
H3a & $\sqrt{ }$ & \\
H3b & $\sqrt{ }$ & \\
H4a & $\sqrt{ }$ & $\sqrt{ }$ \\
H4b & $\sqrt{ }$ \\
H5 & & $\sqrt{ }$ \\
H6a & & \\
H6b & & \\
H7 & & \\
H8a & $\sqrt{ }$ \\
H8b & $\sqrt{ }$ \\
H9 & $\sqrt{ }$ & \\
H10a & $\sqrt{ }$ & \\
H10b & $\sqrt{ }$ & \\
\hline
\end{tabular}




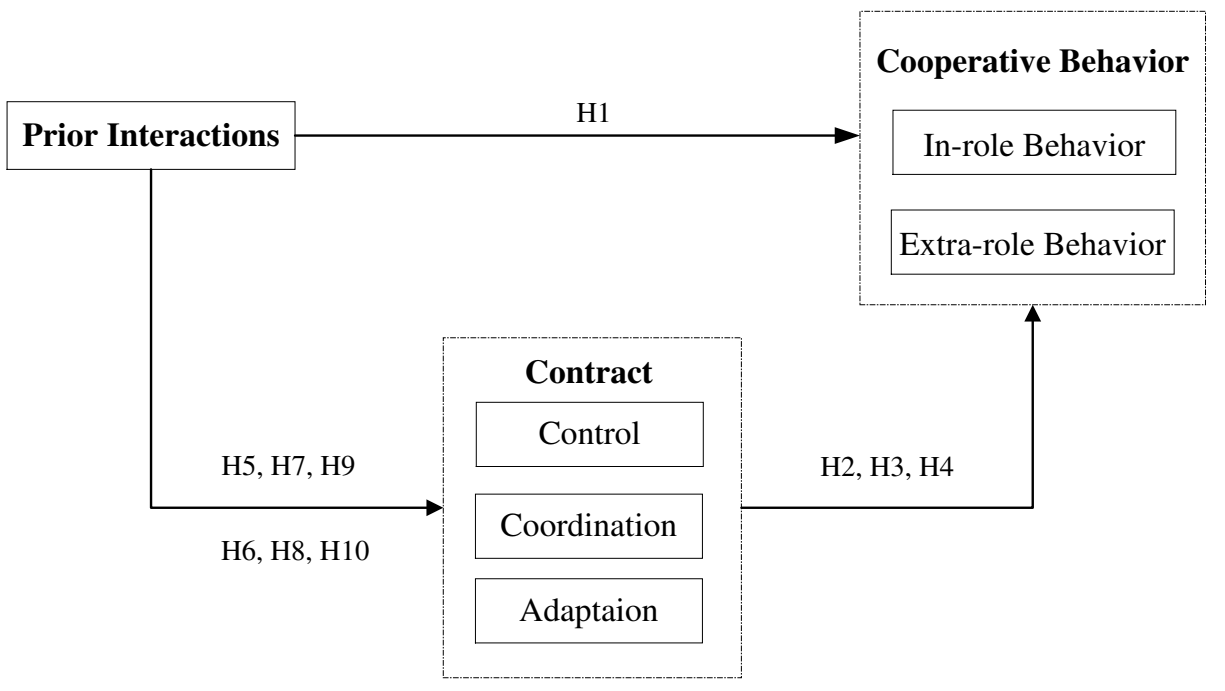

Fig. 1 Research Framework 
- The different paths through which prior interactions affect contract and cooperative behavior is demonstrate.

- The nature of the linkage between the three functions of contract and the two types of cooperative behavior is explicated.

- Increasing contractual coordination emerge from prior interactions, while contractual control and adaptation is not related to these repeated collaborations. 